\title{
Magnetic resonance imaging of sellar and juxtasellar abnormalities in the paediatric population: an imaging review
}

\author{
Rachel Shields • Rajiv Mangla • Jeevak Almast • \\ Steven Meyers
}

Received: 4 November 2014 / Revised: 11 February 2015 / Accepted: 17 February 2015 / Published online: 21 March 2015

(C) The Author(s) 2015. This article is published with open access at Springerlink.com

\begin{abstract}
The sellar and juxtasellar regions in the paediatric population are complex both anatomically and pathologically, with magnetic resonance imaging (MRI) being the "gold standard" imaging modality due to the high contrast of detail. Assessment requires a detailed understanding of the anatomy, embryology, pathophysiology and normal signal characteristics of the pituitary gland and surrounding structures in order to appropriately characterise abnormalities. This article aims to provide an overview of the imaging characteristics of developmental/congenital and acquired disease processes which affect the sellar and juxtasellar region in the paediatric population.

Main Messages

- The sellar region is anatomically complex and covers a wide pathology spectrum.

- MRI is the key imaging modality to assess sellar and juxtasellar pathology.

- Numerous developmental anomalies may not be discovered until adulthood.

- Knowledge of pathology alerts and guides the clinician towards appropriate management.
\end{abstract}

Keywords Magnetic resonance imaging · Paediatrics ·

Pituitary gland $\cdot$ Pituitary diseases $\cdot$ Sella turcica

R. Shields $(\bowtie) \cdot$ R. Mangla $\cdot$ J. Almast $\cdot$ S. Meyers

Department of Imaging Sciences, University of Rochester Medical

Center, 601 Elmwood Ave., Rochester, NY 14642-0001, USA

e-mail: rachel_shields@urmc.rochester.edu

\section{Pituitary function and anatomy}

The pituitary gland is comprised of two dominant lobes, the neurohypophysis and the adenohypophysis. It is situated within the sella turcica, a depression in the sphenoid bone which is covered by the diaphragm sella with a defect for the passage of the infundibulum. The pituitary stalk extends inferiorly as a continuation of the hypothalamic infundibulum (Fig. 1).

The neurohypophysis receives its hormonal supply through direct contiguity with the hypothalamus, with axons extending from the hypothalamic supraoptic and paraventricular nuclei into the neurohypophysis. The hormonal supply includes oxytocin and vasopressin-containing vesicles. The adenohypophysis does not have axonal contiguity between the hypothalamus and the anterior gland and relies on the hypothalamichypophyseal portal system. Parvocellular messengers are transported from the hypothalamic median eminence into the capillaries surrounding the anterior gland. Hormones from the adenohypophysis include: follicle stimulating hormone, luteinising hormone, corticotropin (ACTH), thyroidstimulating hormone, prolactin and growth hormone.

\section{Embryology}

The pituitary gland develops through a complex mechanism involving the developing diencephalon and the primitive oral stomodeum [1]. The adenohypophysis derives from Rathke's pouch, which originates rostral to the oropharyngeal membrane. This begins at approximately 24 days of gestation, in which Rathke's pouch forms as an ectodermal outpouching of stomodeum and the infundibulum which forms in the floor of the diencephalon. The infundibulum grows ventrally, while simultaneously Rathke's pouch grows dorsally. Rathke's pouch eventually loses its connection with the stomodeum 
Fig. 1 Normal pituitary anatomy

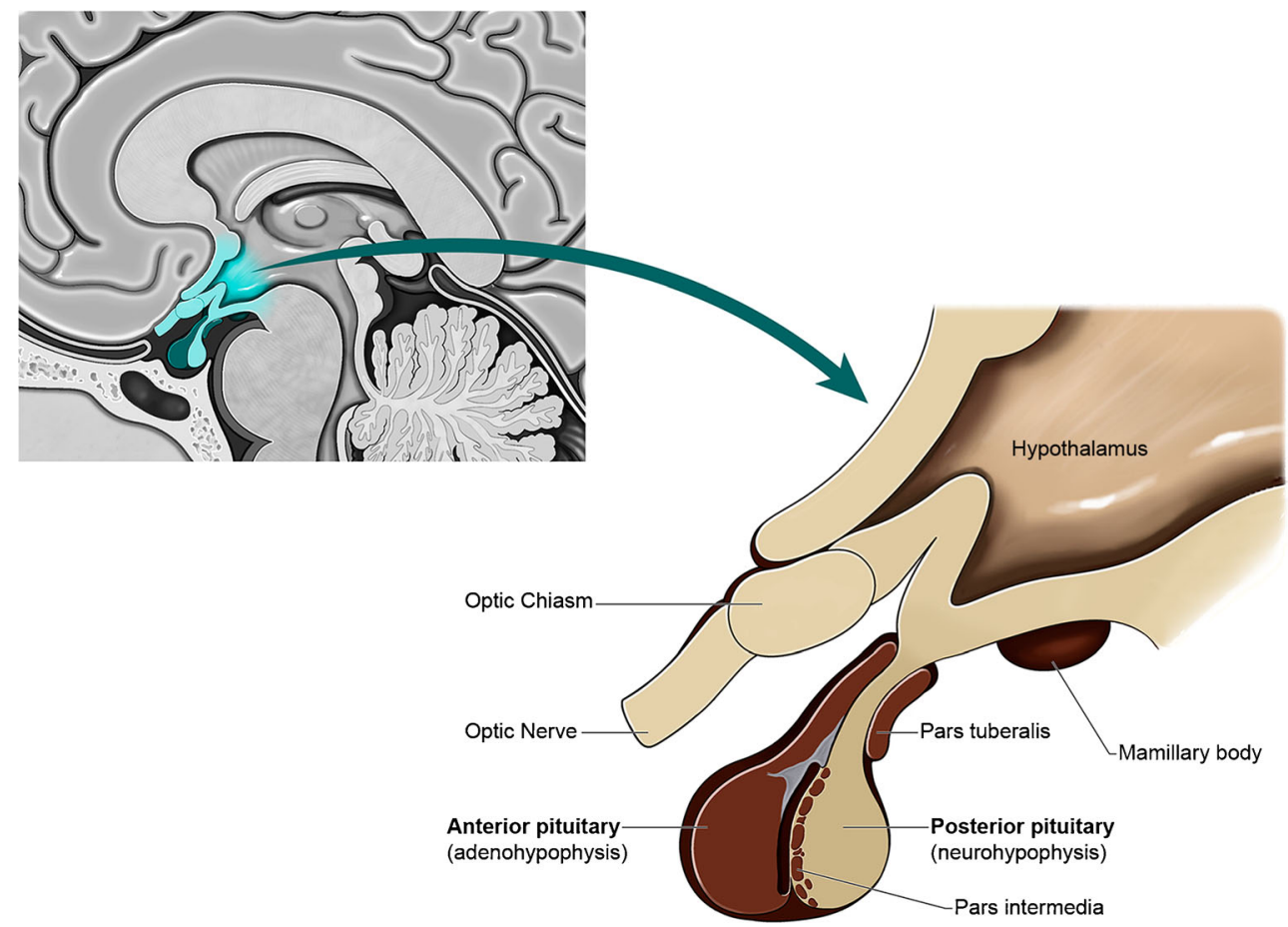

and forms a sac which adheres to the infundibular process. This sac continues to differentiate into the adenophyophysis and the distal aspect of the infundibulum differentiates to form the neurohypophysis (Fig. 2).

\section{Imaging characteristics in the paediatric population}

The pituitary gland exhibits a wide range of appearances during the first 2 years of life, with considerable variability in

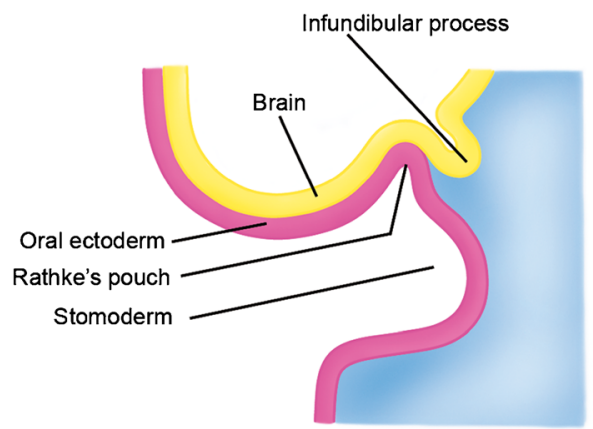

1. Start of development of Rathke's pouch and infundibular process

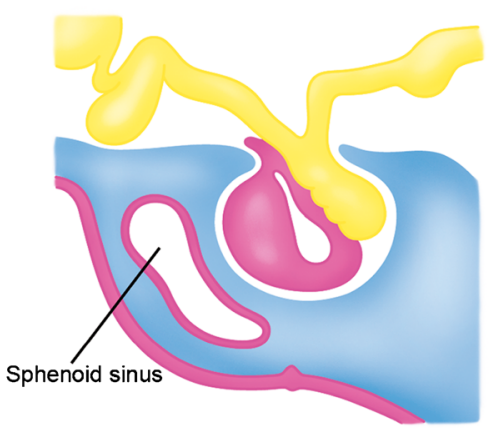

4. "Compressed" segment integrates the neural process, forming pars distalis, pars intermedia, and pars tuberalis

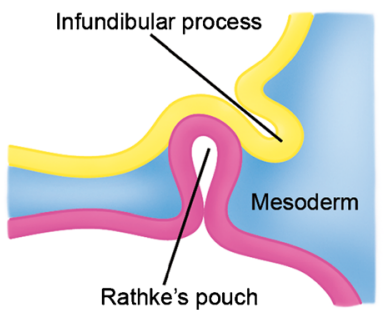

2. Growth of the mesoderm is limited by the neck of Rathke's pouch

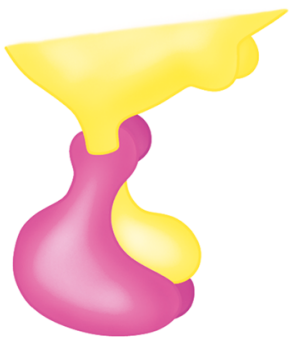

5. Pars tuberalis wraps around the infundibular stalk

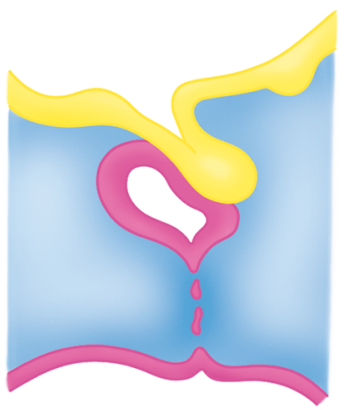

3. Rathke's pouch "compressed"
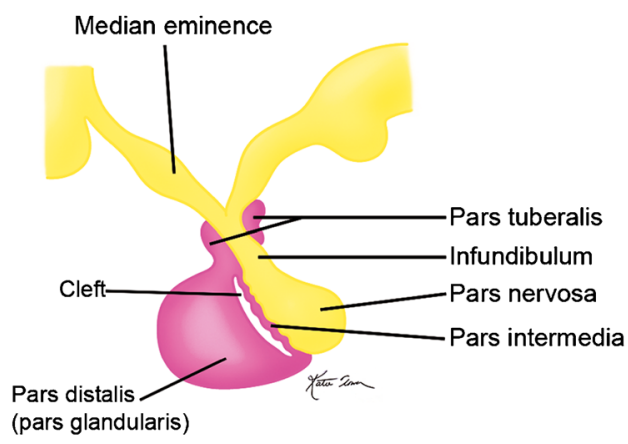

6. Mature form

Fig. 2 Normal development of the pituitary gland 
size, shape, and signal. At birth, both the anterior and posterior pituitary gland have high signal intensity on T1-weighted images (Fig. 3). The anterior pituitary progressively decreases in signal intensity on T1-weighted images with signal drop to near isointensity with the posterior pons by 6 weeks of age $[1,2]$. The posterior pituitary gland retains its high signal intensity on T1-weighted images throughout adulthood, with several papers supporting that this high signal results from neurosecretory granules or the protein neurophysin [3-5]. The normal gland enhances symmetrically after intravenous gadolinium with the anterior gland enhancement appearing more noticeable given the posterior gland is already high signal at baseline.

At birth, the gland is physiologically enlarged with a corresponding concave superior margin, flattening with age. The gland is traditionally symmetric in size; however there can be asymmetry in normally functioning glands. In preterm infants,
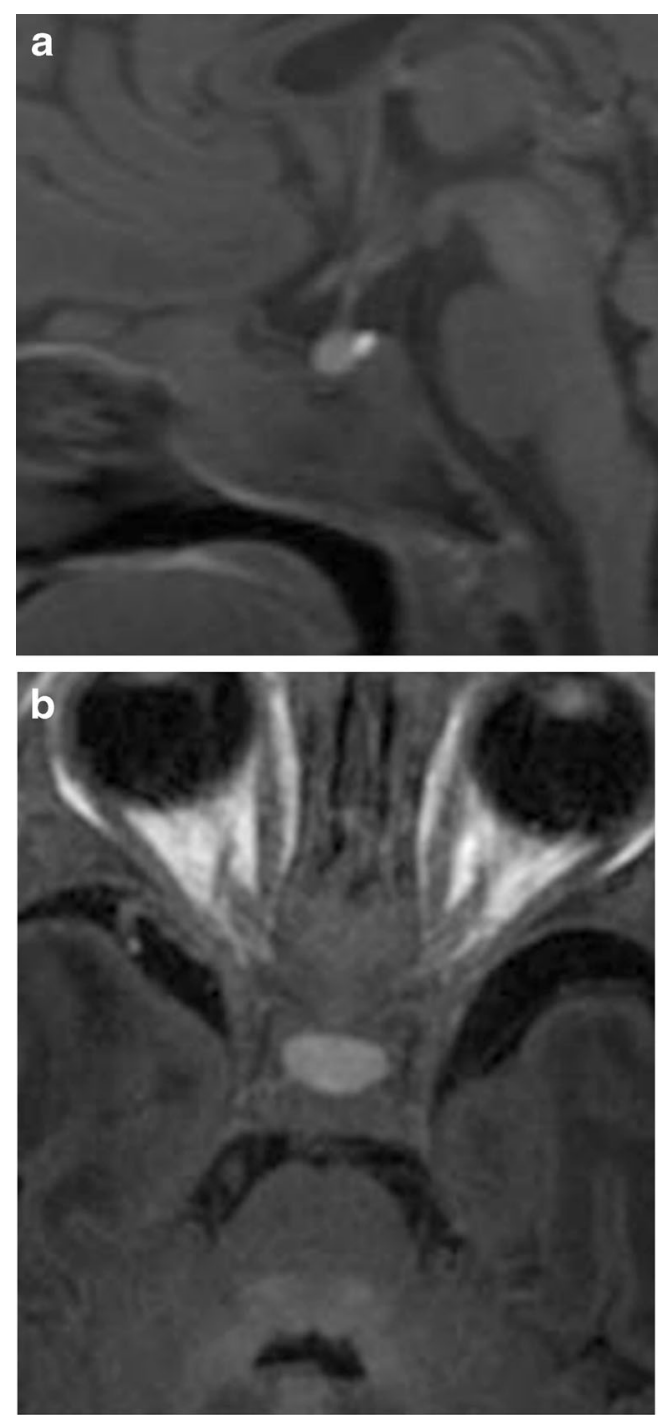

Fig. 3 Normal physiological T1 sagittal (a) and axial (b) hyperintensity of the anterior pituitary in a 1-month-old baby the gland is taller than in normal-term infants, even when correcting for gestational age. This is thought to be the result of reduced insulin-like growth factor 1 and higher levels of growth hormone in premature infants [6]. The pituitary height is fairly stable for the first 2 years of life in normal-term children. Gender-associated differences in the rate of gland growth tend to occur after 5 years of age, with linear growth of the gland up to that point in both boys and girls [7]. Typically, the normal pituitary measures between 2 to $6 \mathrm{~mm}$ in height during childhood and up to $10 \mathrm{~mm}$ or slightly higher at puberty. In adults, the female glands are slightly larger than their male counter parts [1]. Standards for assessing the pituitary stalk size are not well established, and are based on experience rather than age-appropriate measurements. The stalk is best visualised on post-contrast T1-weighted images because of the strong enhancement.

\section{Developmental anomalies of the pituitary gland}

Agenesis of the adenohypophysis (Fig. 4) This is a rare congenital anomaly with a neonatal presentation. The neonates can present with metabolic acidosis, thyroid and adrenal insufficiency, hypoglycaemia, and/or seizures. Associated anomalies of the forebrain and midline craniofacial bones can be present. Newborns are normal in size at birth, which has been explained by the presence of maternal growth hormone. Standard treatment includes replacement of growth hormone, thyroid hormone and glucocorticoids. Magnetic resonance imaging (MRI) findings include the absence of the anterior pituitary gland with an associated shallow sella, and variable length of the infundibulum and position of the posterior pituitary, ranging from the hypothalamus to the sella [8].

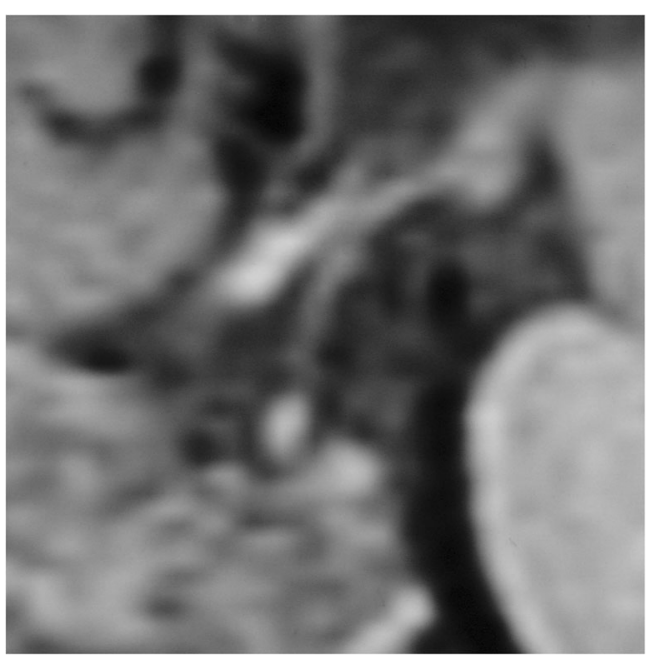

Fig. 4 Agenesis of the anterior pituitary gland (adenohypophysis) in an infant with hypopituitarism. Sagittal T1-weighted imaging (T1WI) shows absence of the adenohypophisis. The stalk terminates into a bulbous neurohypophysis with high signal in the dorsal portion of the sella 
The infundibulum may be thinned and terminate into a partially formed bulbous posterior pituitary gland.

Hypoplasia of the adenohypophysis (Fig. 5) This rare anomaly consists of hypoplasia of the anterior pituitary gland, and also potentially the infundibulum and posterior pituitary gland. It can be associated with varying degrees of endocrine dysfunction, including panhypopituitarism and other congenital anomalies. Some research suggests that traumatic transection of the pituitary stalk during birth or hypoxic injury to the hypothalamus could result in hypoplasia, whereas others suggest an error during embryogenesis [9-12]. MRI findings include varying degrees of hypoplasia of the anterior pituitary gland with variable size and length of the infundibulum. As with agenesis of the adenohypophysis, the posterior pituitary position can range from the hypothalamus to the sella.

Ectopic posterior pituitary (Fig. 6) This congenital anomaly results in an aberrant position of the neurohypophysis, often located at the undersurface of the hypothalamus. It is associated with pituitary dwarfism, delayed skeletal maturation, Kallman syndrome, septo-optic dysplasia, dysgenesis of the corpus callosum, lobar holoprosencephaly, Chiari 1 malformation or a persistent/enlarged craniopharyngeal canal. It affects males more than females. MRI may show a small
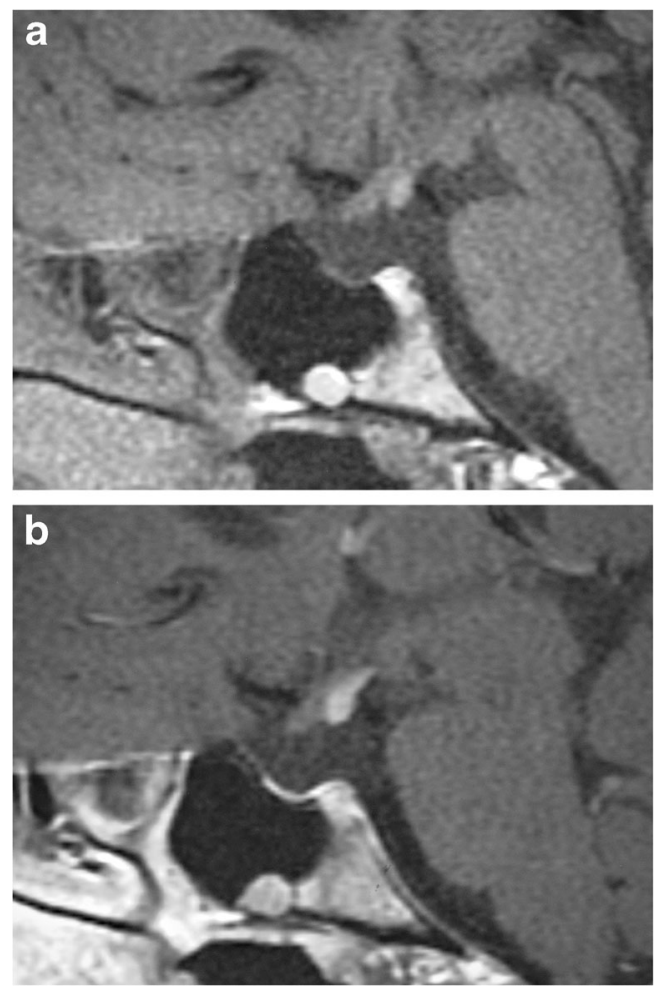

Fig. 5 Severe hypoplasia of the anterior pituitary gland. Pre-contrast (a) and post-contrast (b) MR images show severe hypoplasia of the anterior pituitary gland which shows only minimal contrast enhancement along the floor of the sella. The ectopic posterior pituitary is located adjacent to the optic chiasm
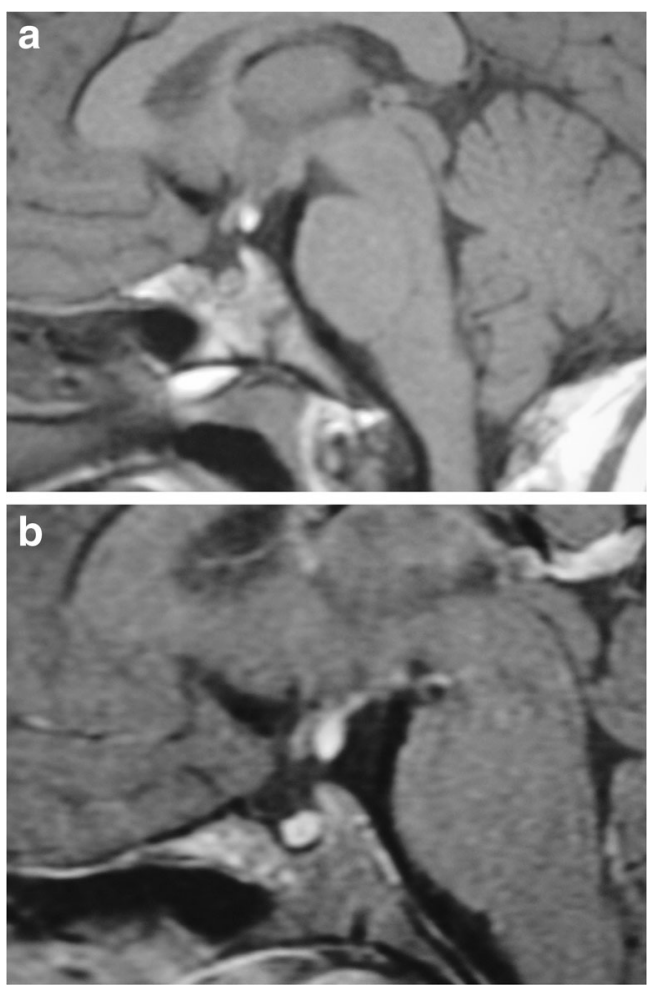

Fig. 6 Ectopic posterior pituitary gland. Pre-contrast (a) and postcontrast (b) MR images show a normal anterior pituitary gland with contrast enhancement and an ectopic posterior pituitary located adjacent to the optic chiasm

anterior pituitary gland with the posterior "bright spot" on T1-weighted imaging (T1WI) located within the upper portion of the infundibulum or the undersurface of the hypothalamus instead of the dorsal portion of the sella [1, 13-15].

Pituitary duplication (Fig. 7) This congenital anomaly is related to abnormal separation of the anterior portion of the notochord and prechordal plate during embryogenesis, likely due to teratogenic factors occurring during early embryogenesis $[16,17]$. Clinical findings include precocious puberty, facial dysmorphism, hypothyroidism and/or increased prolactin levels. Pituitary duplication may be associated with other anomalies such as dysgenesis of the corpus callosum, absent olfactory bulbs, cerebellar hypoplasia, midline defects, and teratomas. MRI findings include duplicated pituitary stalks and glands within separate pituitary fossa in the sphenoid bone. Abnormal thickening, "pseudohamartoma", of the hypothalamus with duplication of the infundibular recess of the third ventricle is often seen $[16,18]$. Pituitary duplication can also be associated with duplication of the basilar artery [19].

Hypothalamic hamartoma (Figs. 8 and 9) Congenital developmental non-neoplastic grey matter heterotopia involving the tuber cinereum, inferior hypothalamus and/or mammillary bodies which are composed of small neuronal cells within a neutrophil-like stroma and scattered fibrillary astrocytes. 

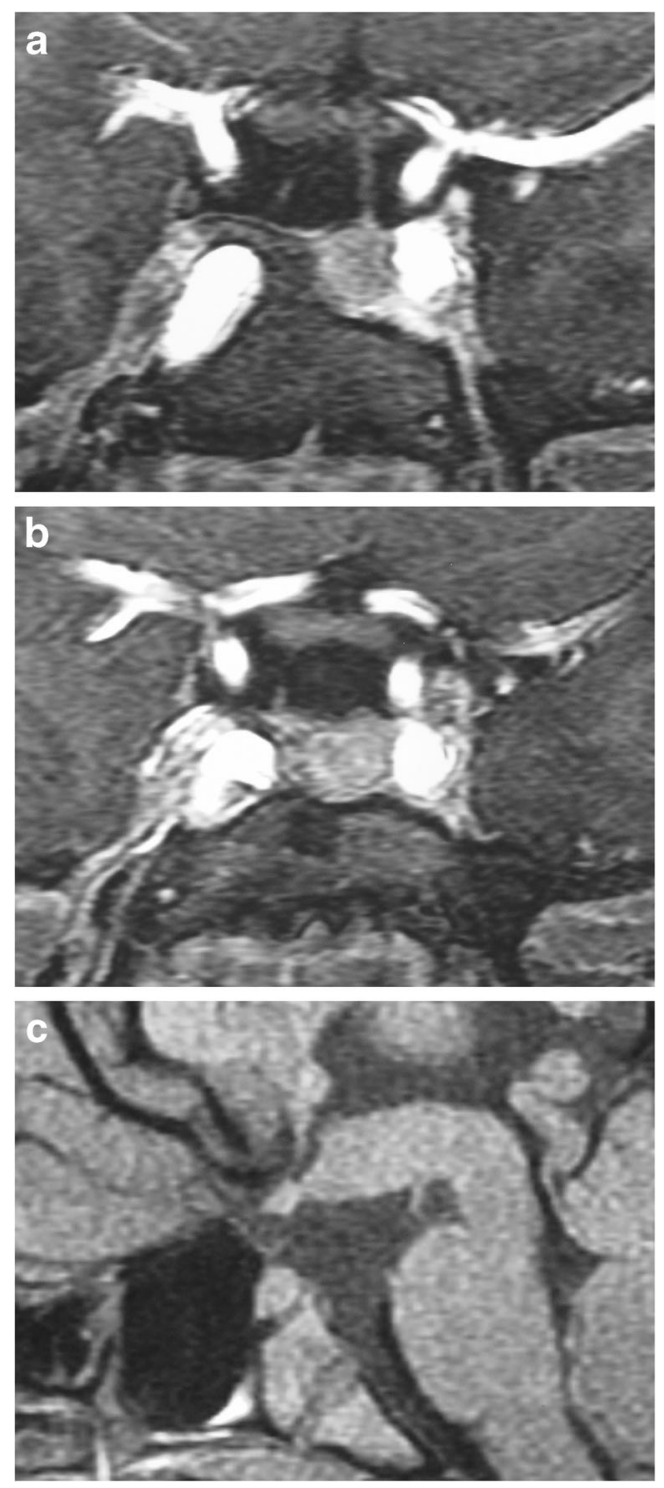

Fig. 7 Pituitary duplication. Coronal post-contrast images (a and b) show two pituitary stalks which extend inferiorly into separate duplicated pituitary glands. Sagittal T1WI (c) shows marked thickening of the hypothalamus, referred to as a pseudohamartoma, which has intermediate signal. The pseudohamartoma showed no contrast enhancement (not shown)

These lesions typically occur in children with isosexual precocious puberty ( $0-8$ years) or seizures, both gelastic or partial complex, in the second decade $[20,21]$. They can be associated with holoprosencephaly, midline facial, cardiac and renal anomalies. MRI demonstrates sessile or pedunculated lesions at the tuber cinereum of the hypothalamus, often intermediate signal on T1WI and T2WI similar to grey matter. Lesions occasionally have slightly high signal on T2WI, with no contrast enhancement or restricted diffusion. Rarely contain cystic and/or fatty portions may be seen in a small minority of cases. The absence of long-term change in size or signal intensity supports the diagnosis [22]. Ictal FDG-PET and SPECT show hyperperfusion during seizures. On MR spectroscopy, there may be an elevated myoinositol peak.

Persistent craniopharyngeal canal (Fig. 10) Lack of involution of the craniopharyngeal canal, which can contain pituitary tissue. The adenohypophysis develops from evagination of ectodermal cells at the upper posterior portion of the primitive oropharynx, Rathke's pouch, at 4-5 weeks of gestation. Rathke's pouch passes between the developing presphenoid and basisphenoid chondrification centres at the upper clivus and sella, where it associates with the descending neuroectoderm of the infundibulum and will go on to form the neurohypophysis. The pathway of Rathke's pouch is the craniopharyngeal canal, which progressively involutes by 6 7 weeks of gestation. The persistent craniopharyngeal canal on MRI can be associated with trans-sphenoidal meningoencephaloceles, ectopic pituitary tissue, sphenoid teratoma and infrasellar craniopharyngiomas [23, 24]. On MRI, the persistent canal has low T1 signal intensity compared with the high T1 signal of the clivus [13].

Rathke's cleft cyst (Fig. 11) Benign cystic lesion containing fluid and variable amounts of protein, mucopolysaccharides and/or cholesterol $[25,26]$. The cysts arise from epithelial rests of the craniopharyngeal canal. They are 2-3 times more common in women than men, and occasionally become symptomatically related to compression of adjacent structures. The frequency of these cysts on MRI in one study was $1.2 \%$ in childhood [27]. MRI will show a well-circumscribed lesion with variable low, intermediate or high signal on T1WI and T2WI. On T2WI, a small low-signal nodule may be seen within the predominant high signal of the lesion, which does not enhance after contrast administration. The incidence of these intracystic nodules varies from 17 to $78 \%[28,29]$. There is no contrast enhancement centrally; however, occasionally there may be a thin peripheral rim of enhancement from associated inflammation. The majority are located in the intrasellar region or combined intrasellar and suprasellar region with reports that only $8.3 \%$ are exclusively suprasellar $[30,31]$. Most are stable in size, and some may disappear spontaneously. Pars intermedia cysts (Fig. 12) can also form along the posterior margin of Rathke's pouch, are typically less than $3 \mathrm{~mm}$, with many considered Rathke's cleft cysts on imaging as they are difficult to distinguish from one another and Rathke's cleft cysts are more common [1].

Cephaloceles (meningoceles or meningoencephaloceles) (Fig. 13) Congenital malformation involving the lack of separation of neuroectoderm from surface ectoderm with resultant localised failure of bone formation. There is a wide range of abnormalities which affect the skull base within the sella turcica, ranging from a persistent craniopharyngeal canal to trans-sphenoidal and sphenoethmoidal cephaloceles, many 
Fig. 8 Hypothalamic hamartoma. Axial T2WI (a) and sagittal T1WI (b) shows a sessile type of hypothalamic hamartoma which has intermediate signal similar to grey matter. Precontrast (c) and post-contrast (d) sagittal T1WI in another patient shows a pedunculated hypothalamic hamartoma with intermediate signal and lacks contrast enhancement
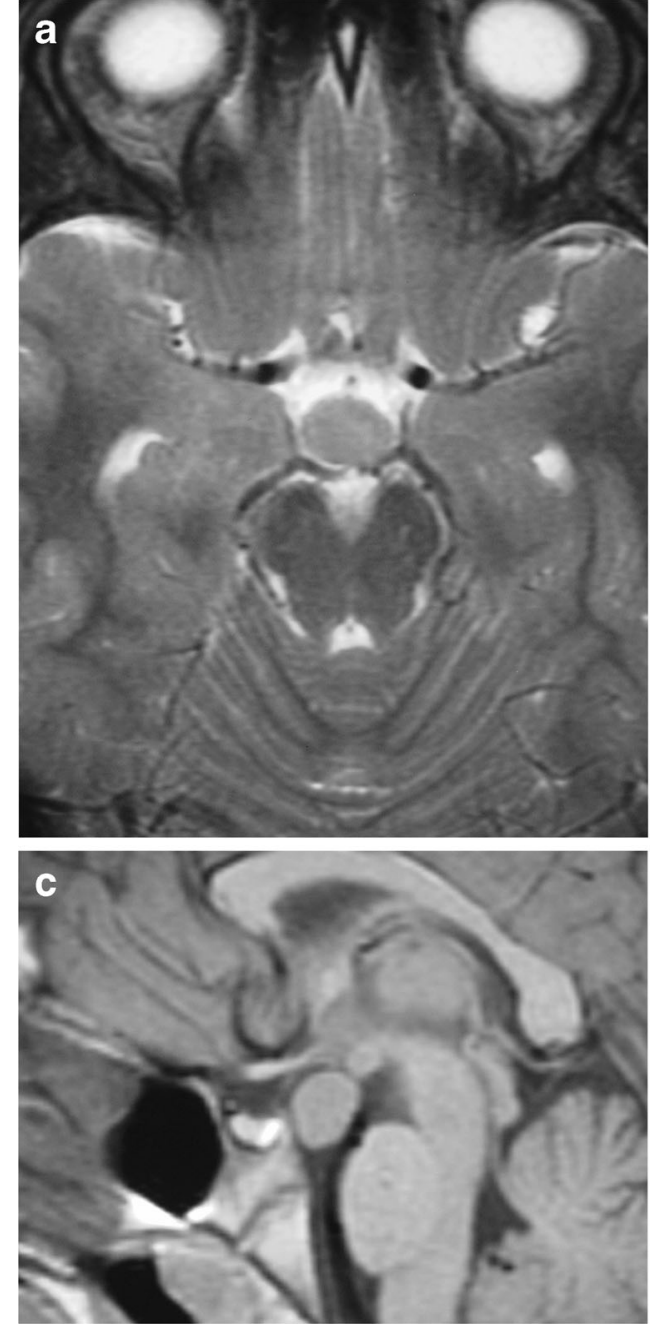
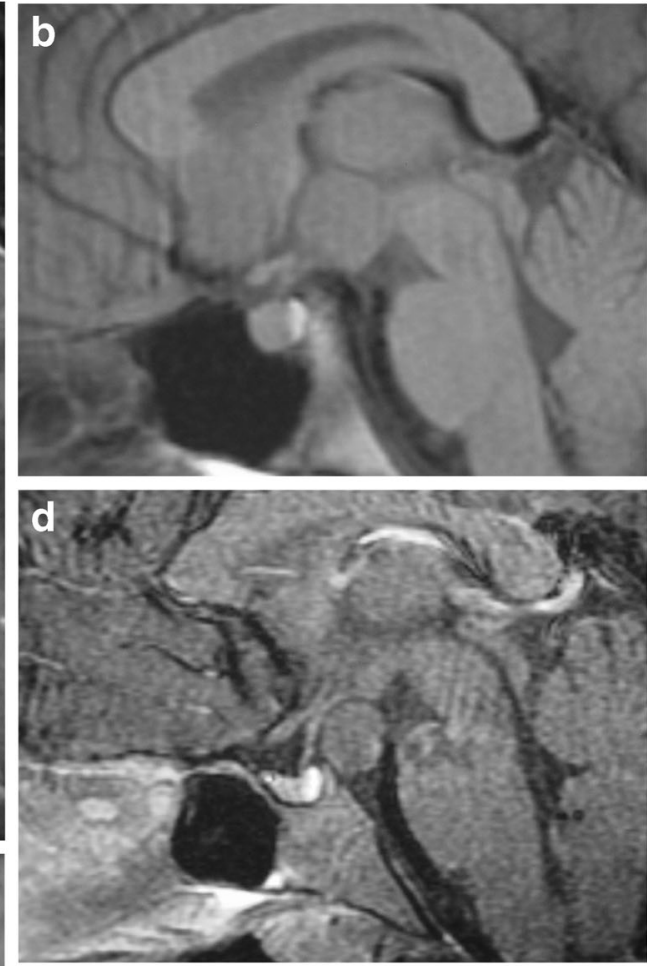

presentations of which are extremely rare. For example, the reported incidence of trans-sphenoidal meningoencephaloceles is 1 per 700,000 live births $[13,32]$. Clinical findings include difficulty in feeding and nasal obstruction in the first year, and potential for cerebrospinal fluid (CSF) leaks and meningitis. MRI will show a defect in the skull, through which there is either herniation of meninges and CSF (meningocele), or meninges, CSF and brain tissue (meningoencephaloceles).

Epidermoid (congenital cholesteatoma) (Fig. 14) Nonneoplastic congenital or acquired extra-axial off-midline lesion filled with desquamated cells and keratinaceous debris, usually with mild mass effect on the adjacent brain. Epidermoids grow by accumulation of desquamated epithelial cells into the centre of the cyst [33-35]. MRI will show a well circumscribed spheroid or multilobulated extra-axial ectodermal inclusion cystic lesion with low-intermediate signal on T1WI, high signal on T2WI and no contrast enhancement. They can be distinguished from arachnoid cysts, as they are typically high signal on FLAIR and DWI sequences, with corresponding low signal on ADC [36].
Dermoid (Fig. 15) Non-neoplastic congenital or acquired ectodermal inclusion cystic lesion, which like an epidermoid, is lined by squamous epithelium, and are filled with lipid material, cholesterol, desquamated cells and keratinaceous debris. They are distinguished from epidermoids by containing deeper dermal elements and commonly arise from the midline. They typically present in the 20- to 30-year age range, but can also be seen in adolescence, with males slightly more affected than females [36]. MRI will show a well-circumscribed spheroid or multilobulated extra-axial lesion, usually with high signal on T1WI, variable signal on T2WI and no contrast enhancement. Fluid/fluid or fluid/debris levels may be present. They can cause a chemical meningitis if the dermoid cyst ruptures into the subarachnoid space $[37,38]$.

Arachnoid cyst (Fig. 16) Congenital arachnoid cysts are found in $0.16 \%$ of all newborns with approximately $9-15 \%$ occurring in the sellar region, with suprasellar cysts more commonly seen than intrasellar cysts. Most cases are asymptomatic; however, they may cause headache, optic nerve compression, psychomotor retardation, endocrine dysfunction or 

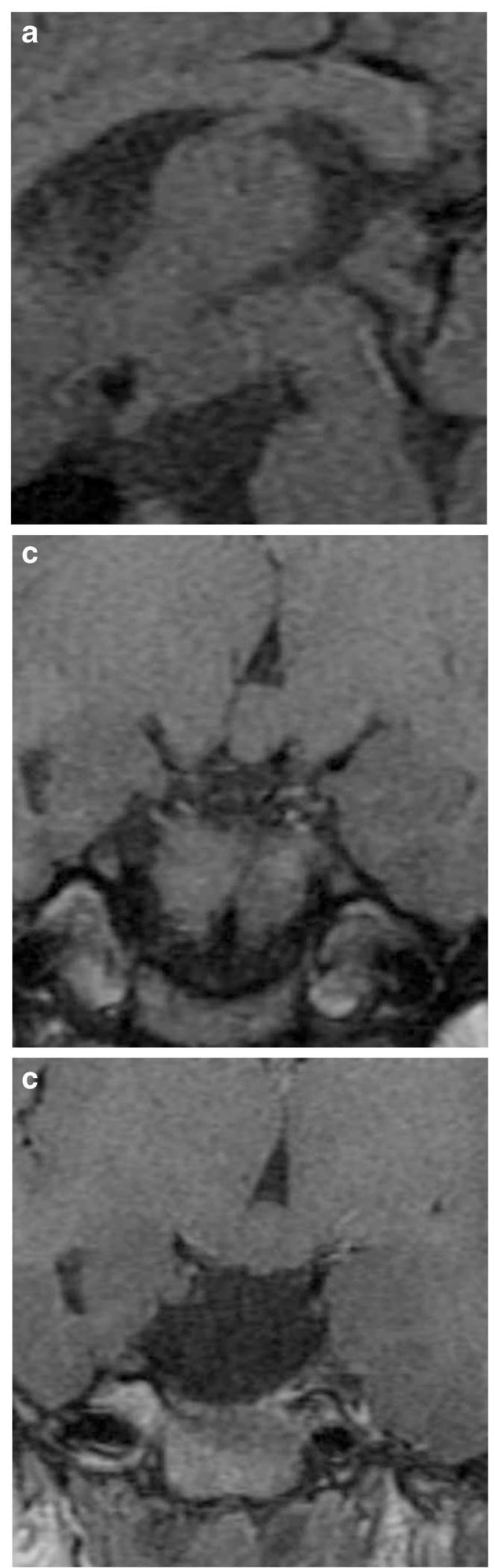

Fig. 9 Tuber cinerum hamartoma. Sagittal (a) and coronal (b) T1WI, and coronal post-contrast T1WI (c) show a non-enhancing bulky soft tissue mass in the region of the of the tuber cinerum
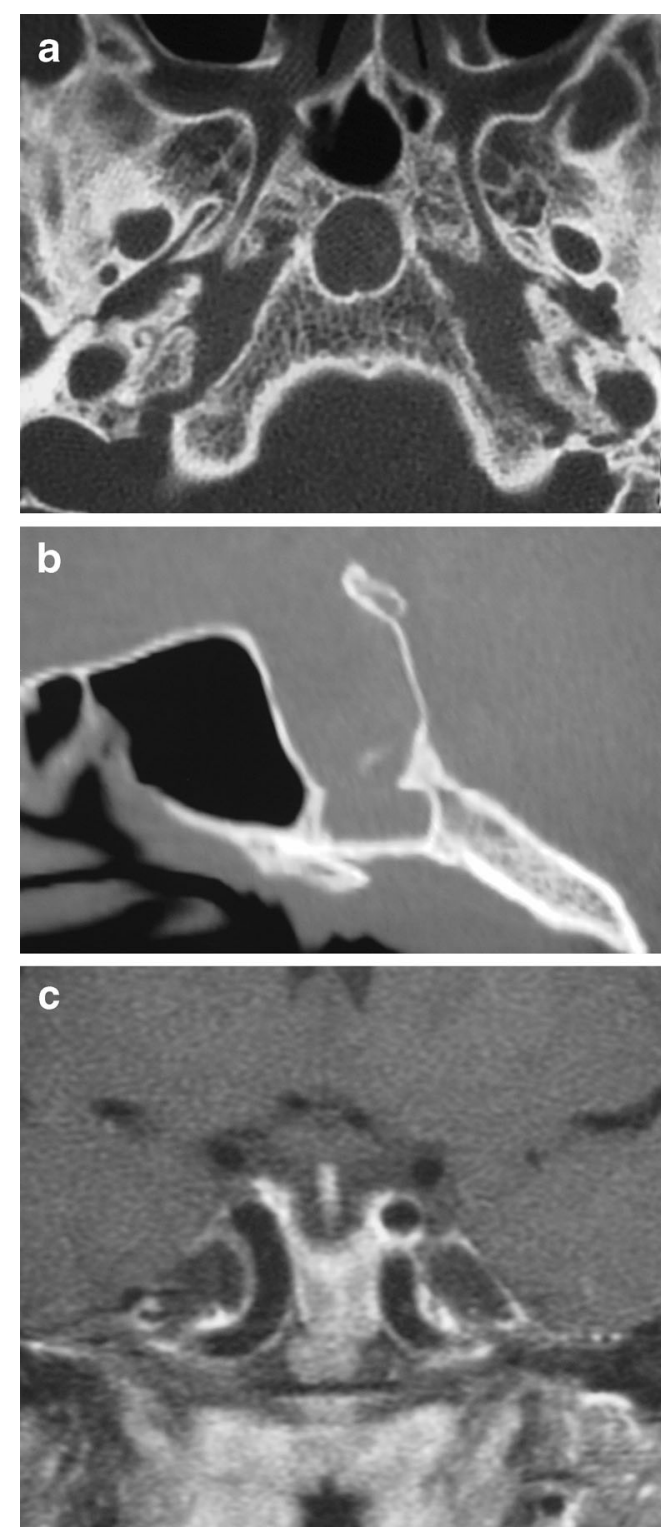

Fig. 10 Persistent craniopharyngeal canal. Axial (a) and sagittal (b) CT shows a markedly enlarged persistent craniopharyngeal canal. Coronal fat-suppressed T1WI shows inferior extension of enhancing pituitary tissue within the abnormally enlarged craniopharyngeal canal (c)

hydrocephalus $[39,40]$. Secondary arachnoid cysts may result from trauma, haemorrhage or infection [41]. On imaging, the cysts have low signal intensity on T1WI, FLAIR and DWI, high signal intensity on T2WI, no contrast enhancement, and may cause mild mass effect on adjacent brain.

Lipoma (Fig. 17) Benign fatty lesions resulting from a congenital malformation, often located at or near the midline. In the sellar region, they occur along the surface of the infundibulum, floor of the third ventricle, or adjacent to cranial nerves, and are usually discovered incidentally, unless they cause a mass effect $[42,43]$. They may contain calcifications and/or traverse blood vessels. MRI signal is 

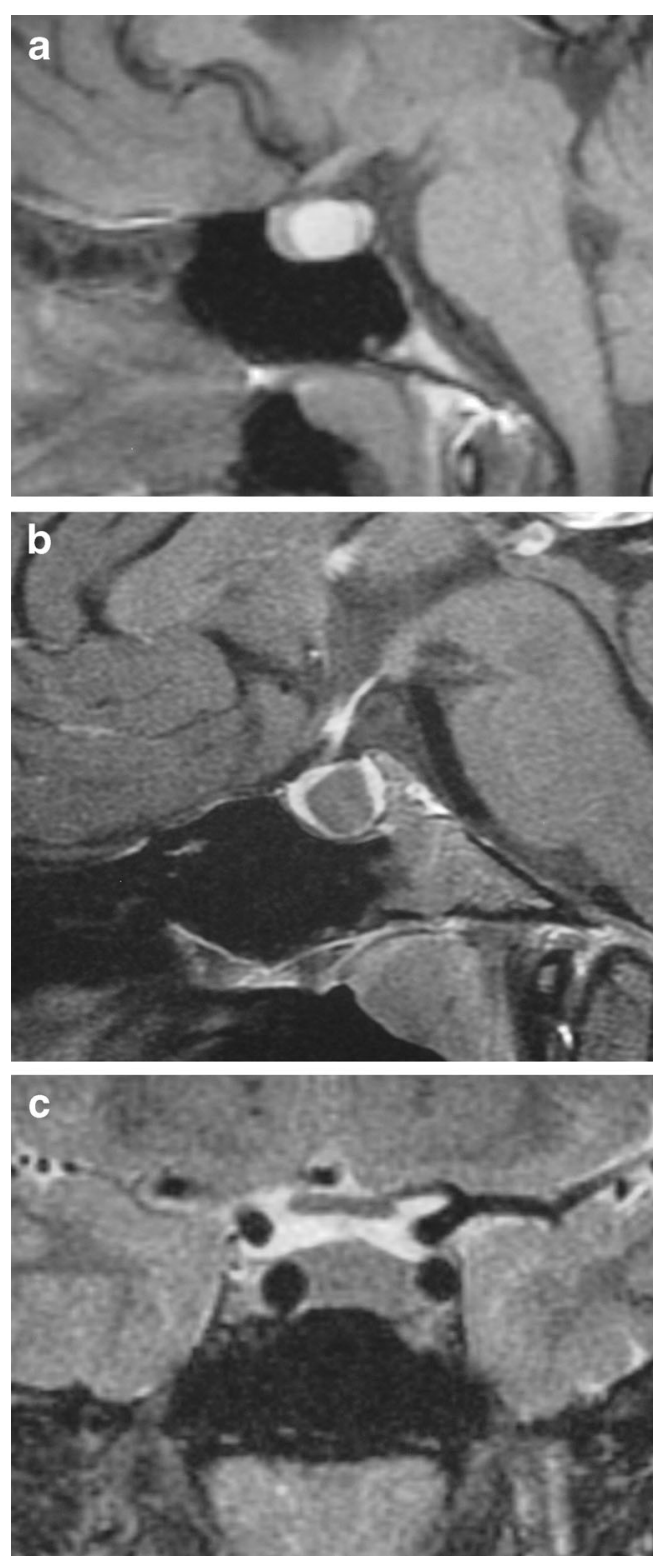

Fig. 11 Rathke's cleft cyst. Sagittal T1WI (a) shows a lesion in the central portion of the pituitary gland which has high signal. Postcontrast sagittal fat-suppressed T1WI (b) shows lack of enhancement of the Rathke cleft cyst. The cyst has intermediate signal on T2WI (c) secondary to slightly elevated protein content

isointense to subcutaneous fat on all sequences, with fat suppressed images useful in distinguishing from haemorrhagic or proteinaceous lesions.

Empty sella (Fig. 18) Common incidental finding involving the pituitary gland and sella, which can result from a weakened or fenestrated diaphragma sella allowing CSF pulsations to flatten the pituitary gland. They are associated with elevated intracranial pressure, a posteriorly placed optic chiasm, and are considered a normal variant or termed "primary
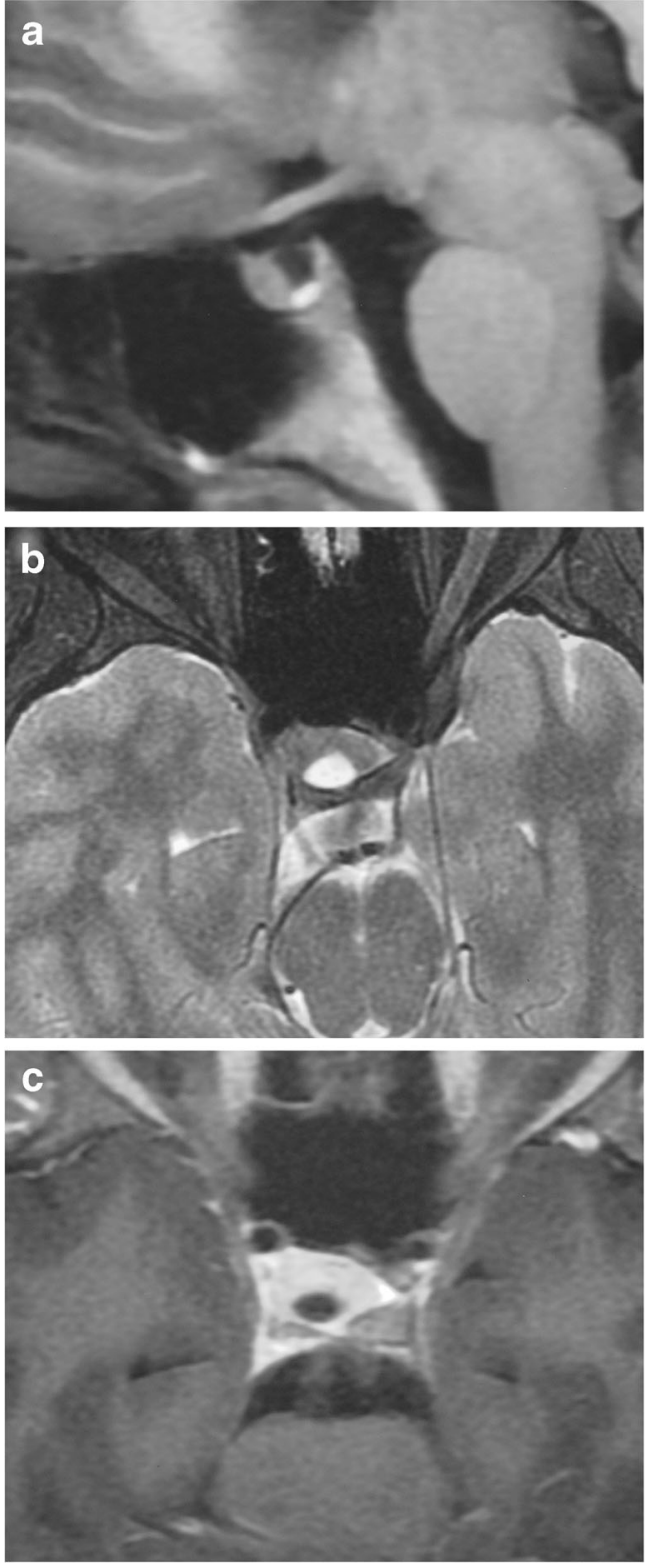

Fig. 12 Pars intermedia cyst. Sagittal T1WI (a) and axial T2WI (b) shows a small cyst between the anterior and posterior pituitary which lacks contrast enhancement on axial fat-suppressed T1WI (c)

empty sella turcica" in the absence of surgery, radiation therapy or medically treated intrasellar tumour [44]. In children, the incidence of an empty sella is seen more often in boys and is more likely to be associated with clinical symptoms and endocrinopathies, particularly growth hormone or multiple pituitary hormone deficiencies [45]. MRI findings include a thinned/flattened pituitary gland along the floor of the sella, with the infundibulum in its normal midline position. The flattened pituitary gland has normal MRI signal characteristics and contrast enhancement. 

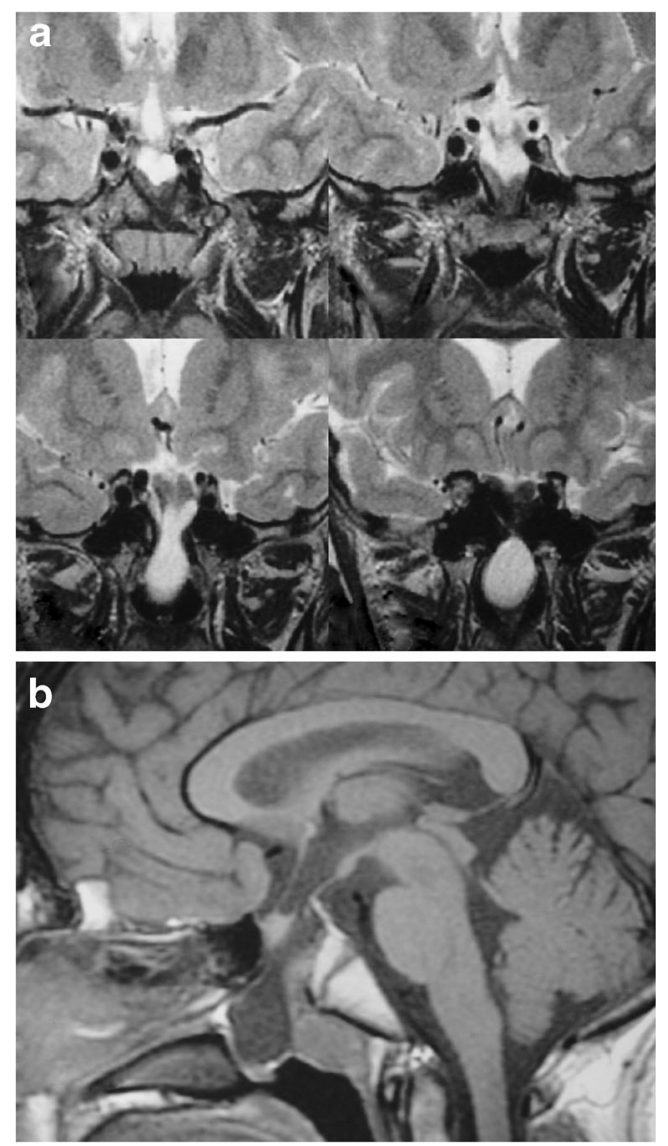

Fig. 13 Cephalocele in a 17-year-old girl. Coronal T2WI (a) and sagittal T1WI (b) shows a meningocele extending inferiorly into the nasopharynx through an osseous defect in the sphenoid bone posterior to the pituitary gland

\section{Pituitary lesions}

Pituitary adenoma (Fig. 19) In comparison to adults, pituitary adenomas are rare in the paediatric population, accounting for approximately $2.7 \%$ of all supratentorial tumours. Most paediatric adenomas are functioning, with only 3-6 \% non-functioning, compared to one-third of nonfunctioning adenomas in adults [46-48]. Microadenomas may be associated with endocrine abnormalities related to over-secretion of hormones, with prolactinomas being the most common. Rarely, extensive haemorrhage can occur involving the adenoma, resulting in pituitary apoplexy (Sheehan syndrome). Macroadenomas with suprasellar extension can cause compression and displacement of the optic chiasm with associated visual disturbances (bitemporal hemianiopsia). Most pituitary adenomas arise from sporadic mutations; however, $5 \%$ can be associated with inherited disorders such as McCune Albright syndrome, Carney complex and multiple endocrine neoplasia type 1 (MEN 1).
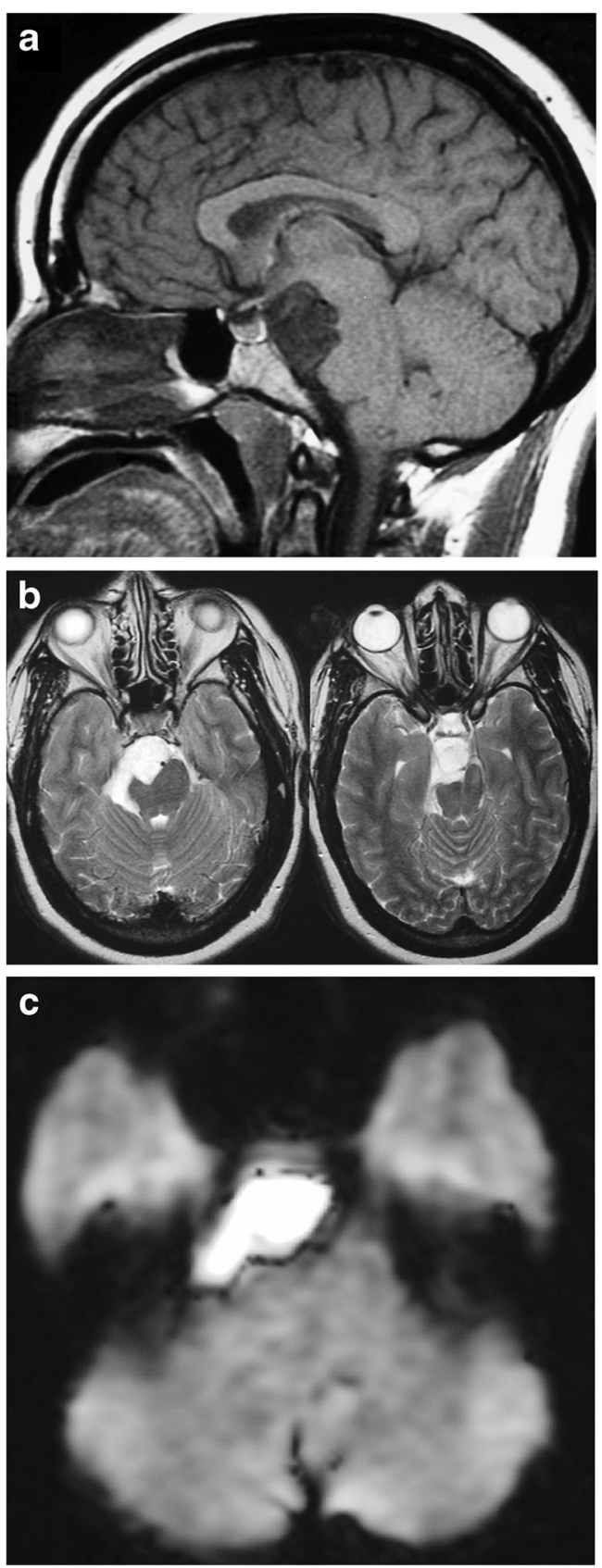

Fig. 14 Epidermoid. Sagittal T1WI (a) shows an extra-axial lesion along the endocranial surface which has heterogeneous mostly low-intermdiate signal, and on T2WI has high signal (b). Diffusion-weighted imaging (DWI) (c) shows restricted diffusion

MRI findings of a microadenoma $(<10 \mathrm{~mm})$ commonly have intermediate signal on T1WI and T2WI, and may show characteristics of cysts, haemorrhage or necrosis. They typically show less contrast enhancement than normal pituitary tissue, often best visualised with dynamic early-phase imaging. In macroadenomas $(>10 \mathrm{~mm})$, they commonly have intermediate signal on T1WI and T2WI similar to grey matter, and may 

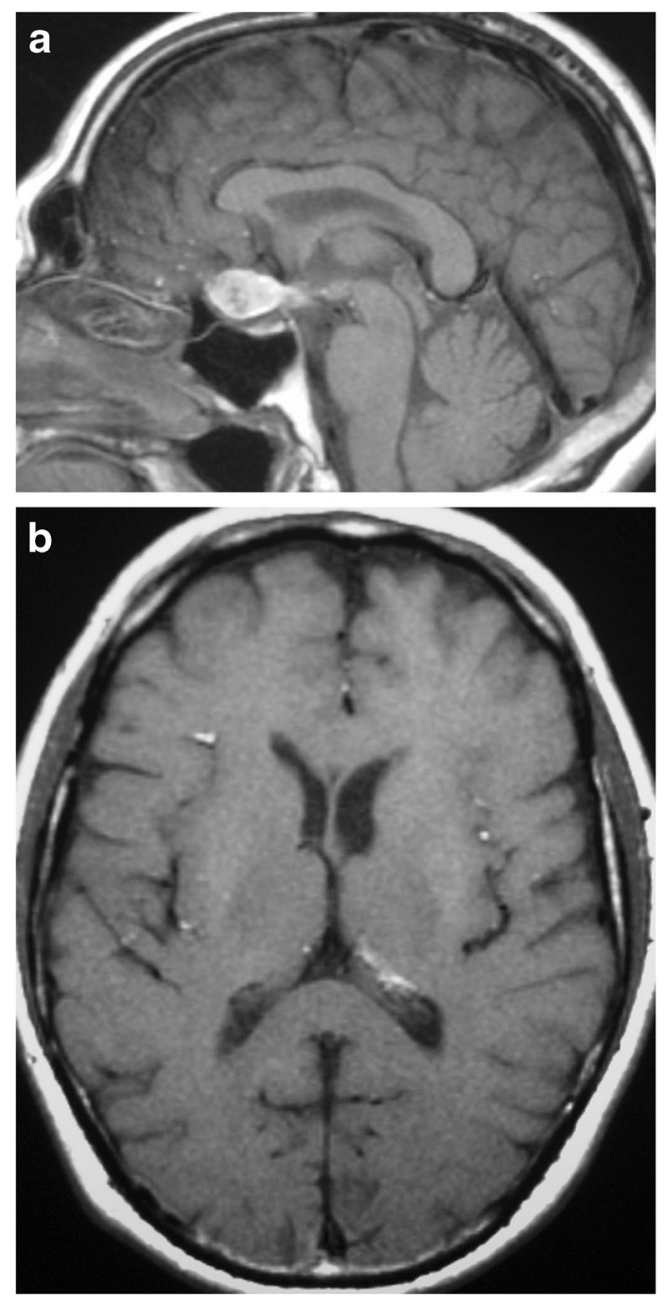

Fig. 15 Dermoid. Sagittal (a) and axial (b) T1WI shows an extra-axial lesion in the suprasellar cistern which has high signal. Multiple small foci with high signal are seen in the sulci and within the left lateral ventricle representing ruptured dermoid contents in the leptomeninges

also have cystic, haemorrhagic or necrotic components. They can extend into the suprasellar cistern with a waist at the diaphragm sella or into the cavernous sinus, with occasional invasion into the skull base.

\section{Juxtasellar lesions}

Craniopharyngioma (Fig. 20) Usually histologically benign locally aggressive lesions which arise from squamous epithelial rests along Rathke's cleft, occurring in a bimodal age distribution, in children $(<10$ years $)$ and adults $(>40$ years $)$. Craniopharyngioma's account for $3 \%$ of all intracranial tumours. They are categorised into adamantinomatous and squamous-papillary types. The adamantinomatous type is more common and has a bimodal age distribution occurring in children and adults, whereas the squamous-papillary type usually occurs in adults. Although histologically benign, their
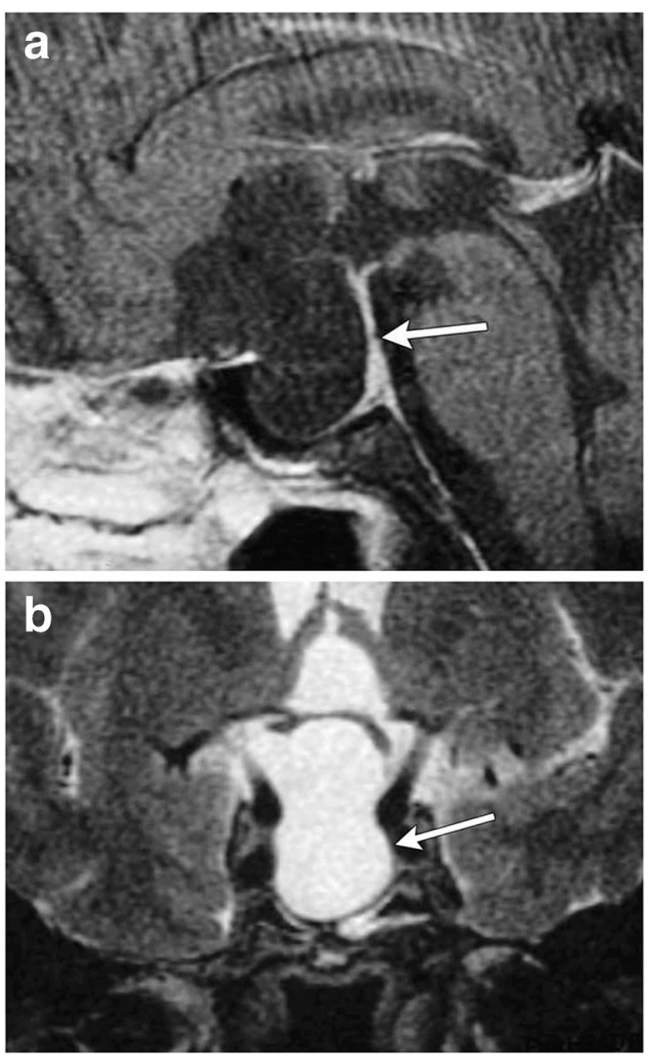

Fig. 16 Arachnoid cyst. Sagittal T1WI (a) and coronal T2WI (b) show a well defined cystic mass with low T1 and high T2 signal intensity with sellar and suprasellar components
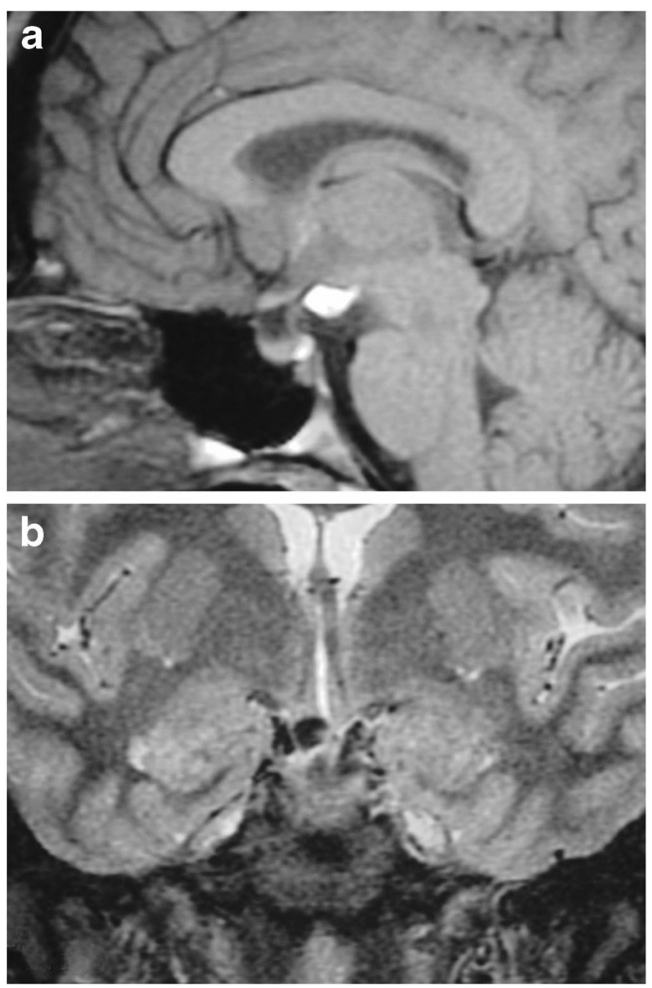

Fig. 17 Lipoma. Sagittal T1WI (a) shows a lipoma with high signal along the inferior surface of the hypothalamus. The signal on the lipoma is nulled on coronal fat-suppressed T2WI (b) 


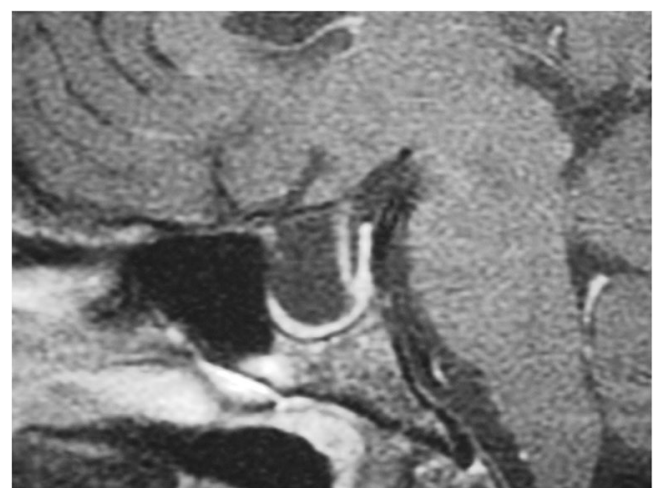

Fig. 18 Empty sella. Sagittal post-contrast T1WI with fat-suppression show an enlarged sella mostly filled with CSF. The enhancing flattened pituitary tissue is located along the floor of the sella

insinuating pattern of growth makes complete surgical excision very difficult and not often possible.

The adamantinomatous type usually demonstrates circumscribed lobulated margins on MRI, with the suprasellar location seen at a greater frequency than intrasellar. They show variable low, intermediate and/or high signal on T1WI and T2WI, with or without a nodular or rim of contrast enhancement. They may contain cysts, lipid components and calcifications. In children, the cystic parts tend to predominate, and frequently contain highly proteinaceous fluid, which may be bright on T1WI [49].

Glioma (Fig. 21) Lesions which may occur anywhere along the optic pathway and account for 4-6\% of brain tumours in children, with a median age of diagnosis from 5-9 years. Approximately half of patients with optic pathway gliomas have neurofibromatosis type 1 (NF1), with symptomatic lesions only occurring in 1-5\% of patients [50]. Most tumours are slow growing WHO grade I-II astrocytomas, often the pilocytic type, however tumours may show a wide spectrum of progression. On MRI, there is fusiform and/or nodular enlargement of the optic chiasm and/or optic nerves with thickening of the third ventricular floor and hypothalamus. They usually have low-intermediate signal on T1WI, intermediatehigh signal on T2WI and variable contrast enhancement. Larger lesions may have cystic components and grow directly into the pituitary stalk [1].

Pilomyxoid astrocytoma (Fig. 22) Rare neoplasms (WHO grade II) which contain prominent mucoid matrix and angiocentric pattern of bipolar neoplastic astrocytes. Typically, they occur in children in the first and second decades, with a mean age of 7 years [51]. They tend to occur at a younger age and are more aggressive with a higher rate of local recurrence than pilocytic astromcytomas. They have a strong predilection for the hypothalamus and suprasellar cistern [52]; however, they can also occur in the thalamus, cerebellum,
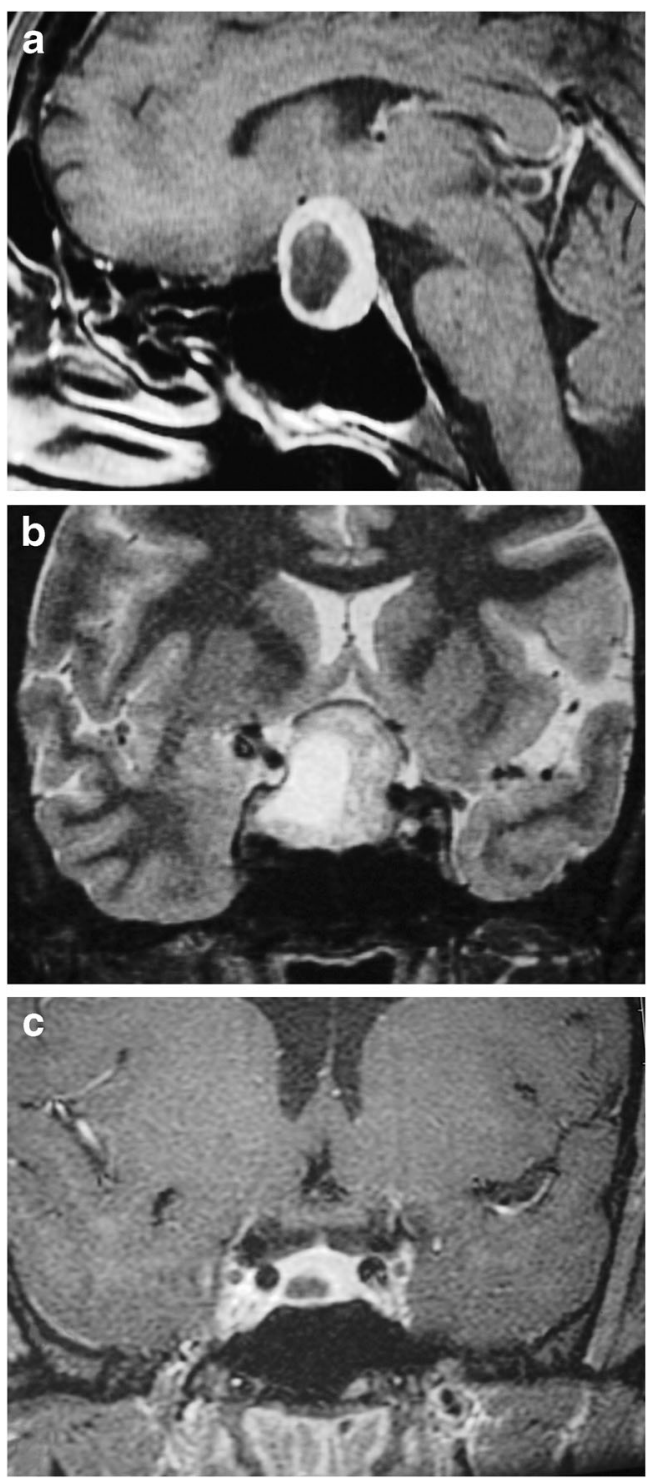

Fig. 19 Pituitary adenomas. Sagittal post-contrast fat-suppressed T1WI (a) shows an heterogenously enhancing pituitary macroadenoma which contains a non-enhancing portion with high signal on T2WI (b). secondary to cystic degeneration. Coronal post-contrast fat-suppressed T1WI (c) shows a pituitary microadenoma which shows less early contrast enhancement than the normal pituitary tissue

brainstem, temporal lobe and spinal cord. The presence of intra-tumoural haemorrhage is the most prominent imaging characteristic to suggest a pilomyxoid astrocytoma over a pilocytic astrocytoma, $25 \%$ versus $8 \%$, respectively [51]. MRI demonstrates a solid/cystic focal lesion with lowintermediate signal on T1WI, high signal on T2WI and FLAIR, variable contrast enhancement and may show increased ADC values.

Germ cell tumours-germinoma (Fig. 23) Extra-gonadal germ cell tumours include: germinoma (most common), mature teratoma, malignant teratoma, yolk sac tumour, embryonal carcinoma and choriocarcinoma. They account for $0.6 \%$ 

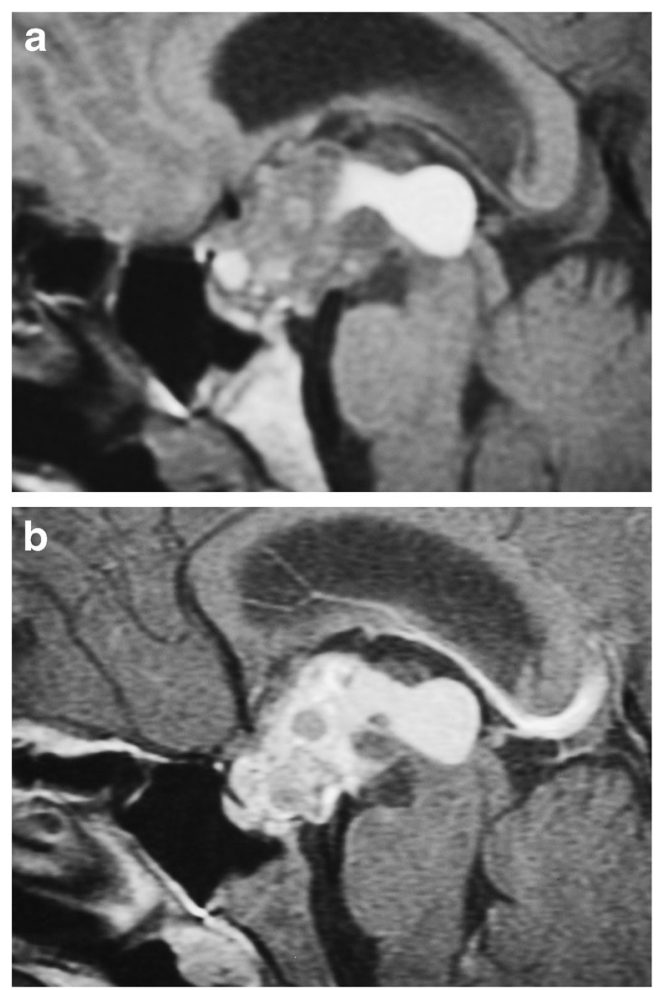

Fig. 20 Craniopharyngioma. Sagittal T1WI (a) shows a lobulated lesion filling the suprasellar cistern which contains zones of low, intermediate and high signal. Sagittal post-contrast T1WI (b) shows the lesion to have heterogeneous contrast enhancement

of primary intracranial tumours, with an incidence of 0.09 per 100,000. Peak incidence occurs between 10 and 14 years, with $90 \%$ occurring in patients less than 25 years. They occur more frequently in males. Prognosis depends on the histological subtype, with a 10 year survival rate for germinomas of over $85 \%$. Other germ cell tumours have a lower survival rate, particularly those containing non-germinomatous malignant cells. Tumours often have intermediate signal on T1WI, slightly high signal on T2WI, and show contrast enhancement. They are typically centred on the pituitary stalk with the posterior pituitary bright spot often absent. They may look similar to Langerhans' cell histiocytosis (LCH) or lymphocytic hypophysitis [53]. Contrast-enhancing disseminated subarachnoid and/or intraventricular tumour may occur through CSF seeding.

Germ cell tumours - teratoma (Fig. 24) The second most common type of germ cell tumour behind a germinoma. They occur in children, with a greater frequency in boys, accounting for $0.5-1.5 \%$ of all childhood brain tumours, and $>50 \%$ of intracranial tumours in infants less than 2 months $[54,55]$. Histologically, they demonstrate benign or malignant types, composed of derivatives of ectoderm, mesoderm and/or endoderm. On MRI, they are relatively circumscribed lesions, most common in decreasing order frequency within the pineal region, suprasellar region, and third ventricle. On MRI, they
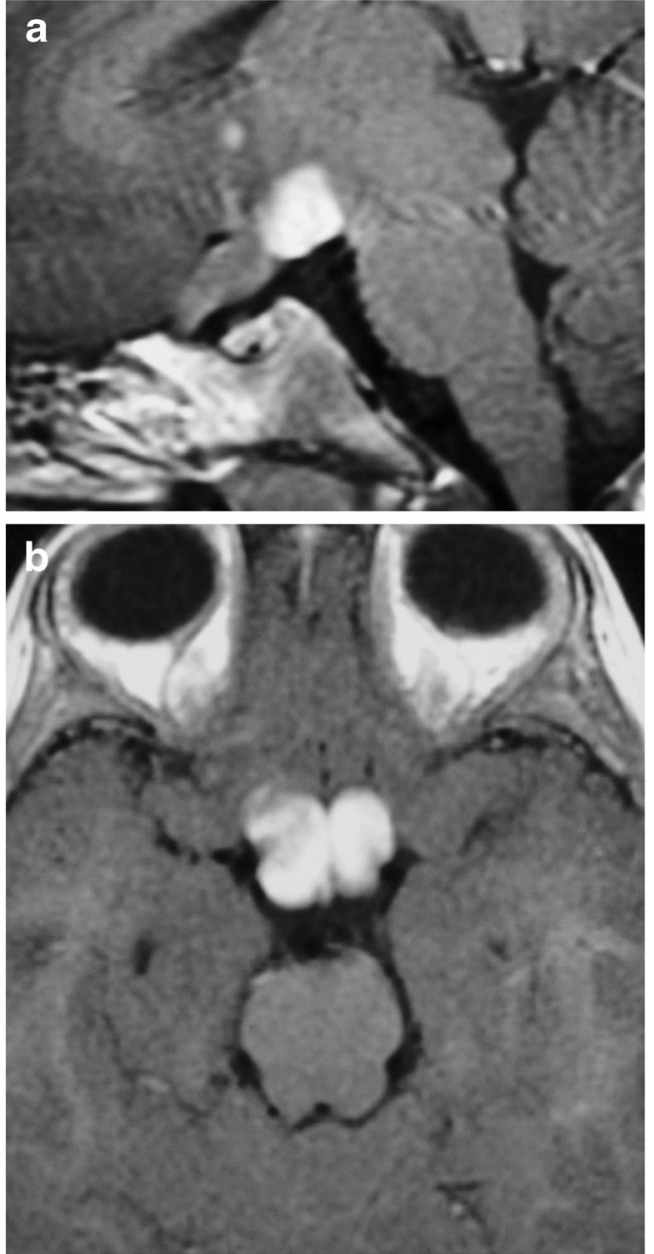

Fig. 21 Glioma in a 2-year-old girl with neurofibromatosis type 1. Sagittal (a) and axial (b) post contrast T1WI shows a partially enhancing lesion enlarging the optic chiasm and proximal optic nerves

demonstrate heterogeneous signal intensity on T1WI, T2WI and post-contrast sequences, with suppression of signal on fatsaturated imaging. Marked enhancement of the solid portions of the tumour is a key feature in distinguishing a mature versus a malignant teratoma, with malignant tumours demonstrating enhancement. Additionally, they typically present without perilesional high T2 signal due to intact capsules and an undamaged blood-brain barrier [55]. They may contain calcifications with low signal on T1WI and T2WI.

Tuberculous meningitis (Fig. 25) Mycobacterium tuberculosis infection remains a major international concern, with increasing burden of disease in developed nations and young children being the most susceptible [56, 57]. MRI is increasingly being used to evaluate patients with suspected tuberculous meningitis, to aid in rapid early diagnosis [58]. MRI findings include basal leptomeningeal enhancement secondary to multiple granulomas and pial tuberculomas. The granulomas can be either non-caseating with homogeneous 

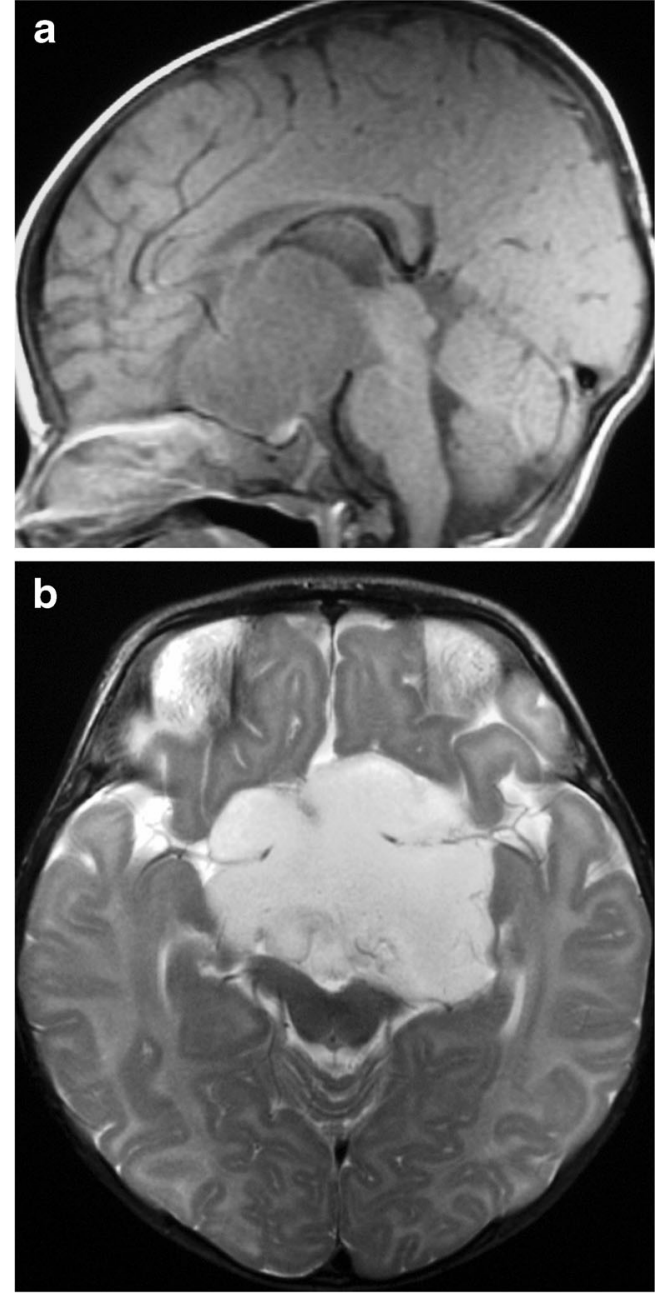

Fig. 22 Pilomyxoid astrocytoma in a 4-month-old baby girl. Sagittal T1WI (a) shows a large hypothalamic lesion with intermediate signal which extends superiorly into and filling the third ventricle, and inferiorly into the suparsellar cistern. The tumour has mostly high signal on axial T2WI (b)

enhancement or caseating with rim enhancement (both $\mathrm{T} 1$ hypointense and $\mathrm{T} 2$ hyperintense) [59].

Osteosarcoma (osteogenic sarcoma) Rare malignant bone tumour comprised of proliferating neoplastic spindle-cells which produce osteoid and/or immature tumoural bone. They usually involve the endochondral bone-forming portions of the skull-base and are locally invasive with high metastatic potential. Over $75 \%$ of osteosarcomas are diagnosed in patients between 8 and 25 years, and account for less than $1 \%$ of all head and neck malignant tumours in the paediatric population [60]. They occur in children as primary tumours and adults associated with Paget's disease, irradiated bone, chronic osteomyelitis, osteoblastoma, giant cell tumour and fibrous dysplasia. MRI will show a destructive lesion involving the skull base, with low-intermediate signal on T1WI, mixed low, intermediate or high signal on T2WI. Usually contains matrix
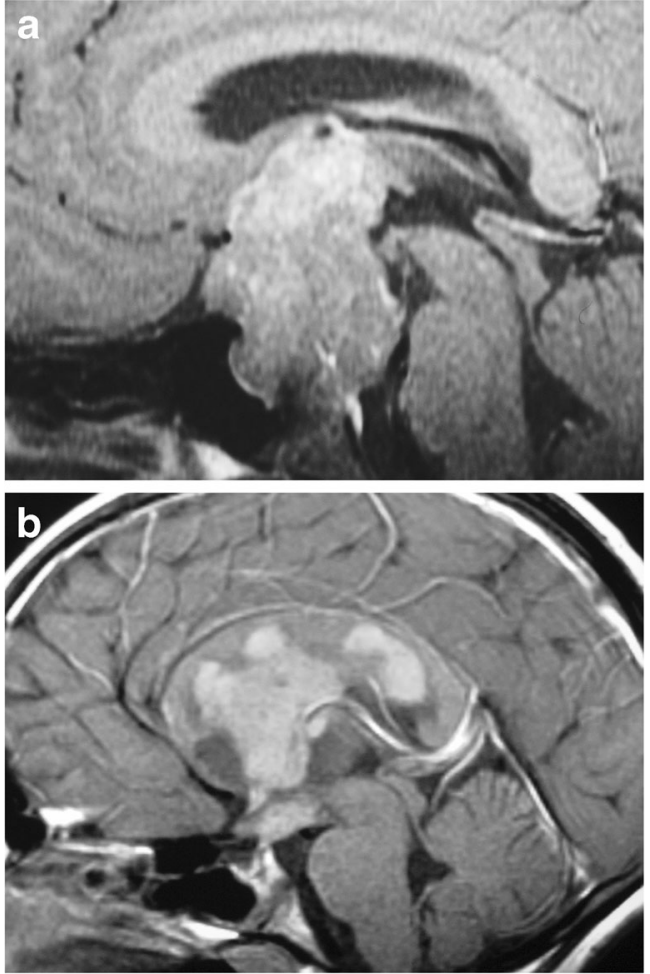

Fig. 23 Germ cell tumours in two different children. Post-contrast T1WI (a) shows a large enhancing lesion in the suprasellar cistern extending superiorly into the third ventricle and posteriorly into the prepontine cistern. Sagittal post-contrast T1WI (b) in another child shows enhancing, disseminated germ-cell tumour in the suprasellar cistern, third and lateral ventricles, with involvement of the corpus callosum and optic chiasm

mineralisation/ossification with low signal on T2WI and heterogeneous contrast enhancement.

Ewing sarcoma Bone tumour usually occurring between ages 5 and 30 years, with a greater prevalence in males and is the second most common primary bone malignancy affecting adolescents and young adults. It most commonly arises in the trunk and diaphysis of long bones, with only $4 \%$ of cases within the head and neck region [61]. Tumours are locally invasive with a high metastatic potential. MRI will show a destructive lesion involving the skull base, with low-intermediate signal on T1WI, mixed low, intermediate or high signal on T2WI, with or without matrix mineralisation showing low signal on $\mathrm{T} 2 \mathrm{WI}$ and heterogeneous contrast enhancement.

Esthesioneuroblastoma (olfactory neuroblastoma) (Fig. 26) These malignant neoplasms of neuroectodermal origin, arise from olfactory epithelium in the upper nasal cavity and cribiform region. Tumours consist of immature neuroblasts with variable nuclear pleomorphism, mitoses and necrosis. Tumour cells occur in aneurofibrillary intercellular matrix. There is a bimodal age of occurrence in adolescents (11-20 years) and adults (50-60 years) [62], with a 

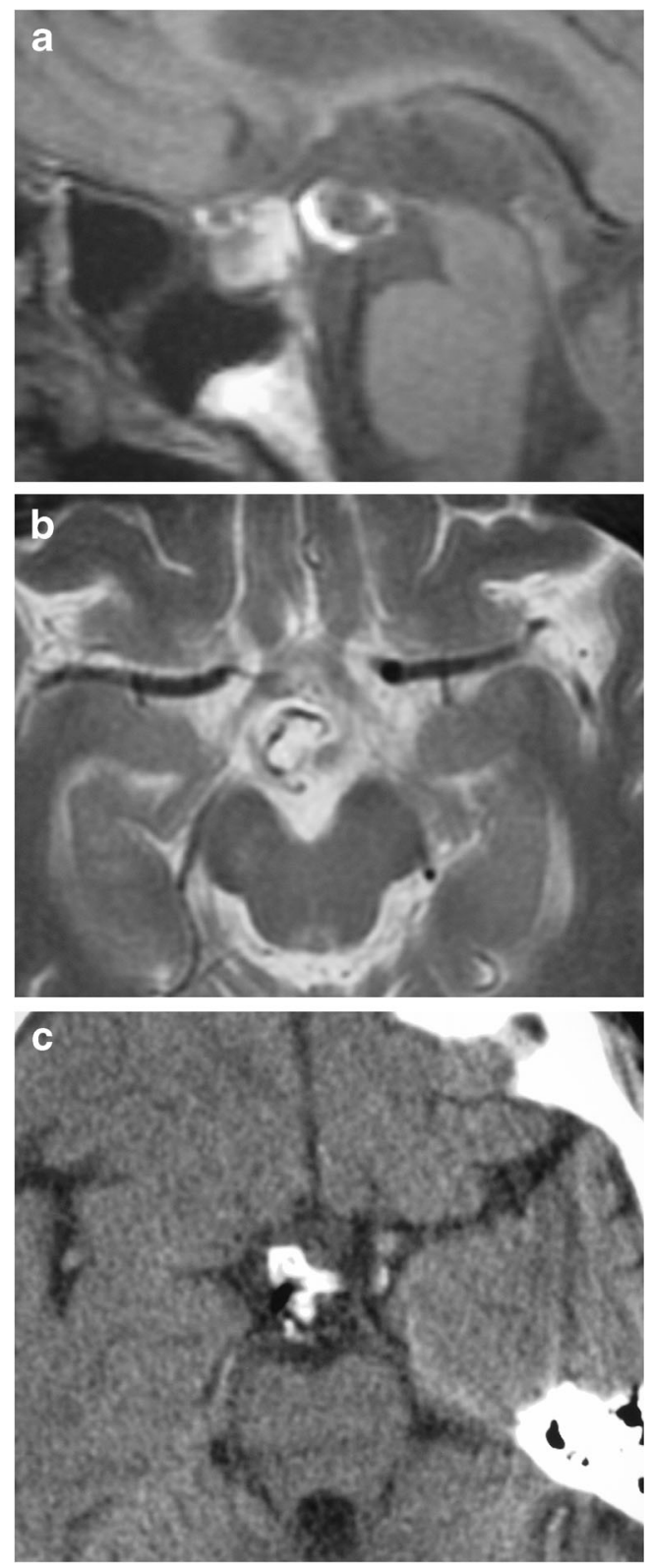

Fig. 24 Teratoma. Sagittal T1WI (a) and axial T2WI (b) show a lesion at the undersurface of the hypothalamus which has mixed low, intermediate and high signal. Axial CT image (c) shows the lesion to contain zones of calcification, fat and intermediate soft-tissue attenuation

greater prevalence in males. On MRI, they present as a locally destructive lesion with low-intermediate signal on T1WI, intermediate-high signal on T2WI and prominent contrast en-

Fig. 25 A 4-month-old baby boy with tuberculous meningitis. Axial (a, b) and coronal (c) post-contrast T1WI shows prominent extra-axial contrast-enhancement in the basal meninges, surrounding the brainstem, cerebellar sulci and Sylvian fissures. The leptomeningeal infection invades the left temporal lobe
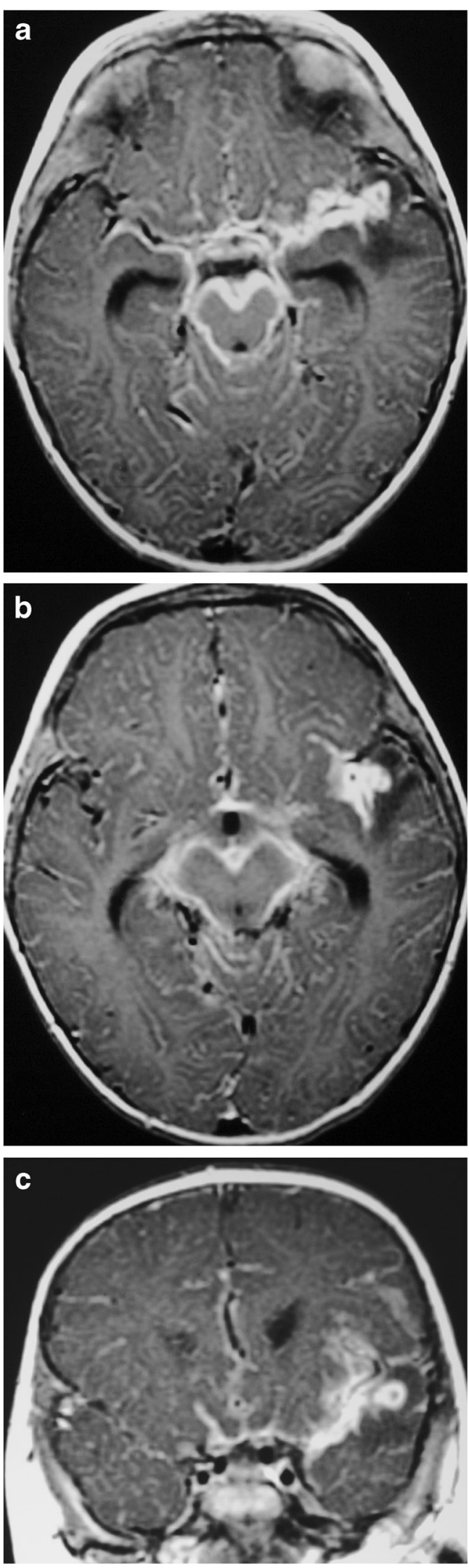

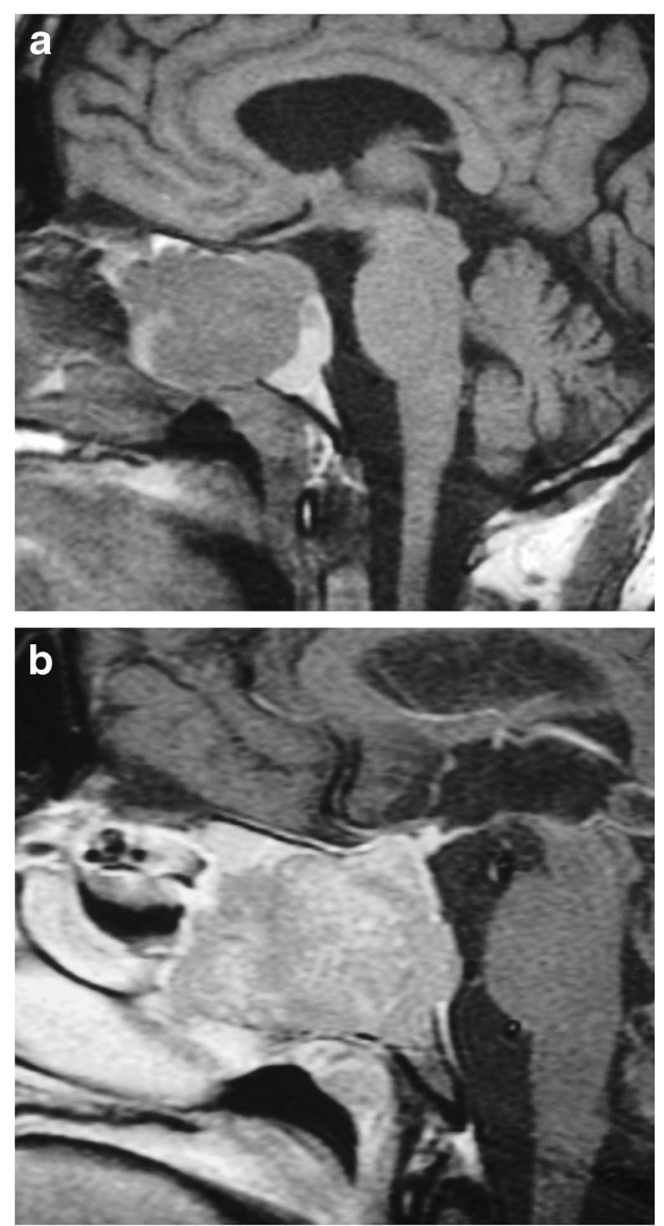

Fig. 26 Enthesioneuroblastoma. Sagittal T1WI (a) and post-contrast T1WI (b) show a destructive mass lesion involving the sphenoid bone which invades the sphenoid sinus and sella. The tumour shows prominent, mildly heterogeneous contrast enhancement

hancement. They are commonly located within the superior nasal cavity, ethmoid air cells with occasional extension into other paranasal sinuses, orbits, anterior cranial fossa, and cavernous sinuses. Positron emission tomography (PET)/computed tomography (CT) can be useful for staging of disease and detection of metastases [63].

Fibrous dysplasia (Fig. 27) Benign medullary fibroosseous lesion, which can involve a single site (monoostotic) or multiple locations (poly-ostotic), results from developmental failure in the normal process of remodelling primi-

Fig. 27 Fibrous dysplasia in a 5-year-old girl with McCune Albright syndrome. Axial CT (a) shows multiple expansile lesions involving the skull which have a "ground glass" appearance representing sites of polyostotic fibrous dysplasia. Sagittal T1WI shows expansion of the clivus which has diffuse low signal (b) with corresponding diffuse enhancement on sagittal post-contrast fat-suppressed T1WI (c)
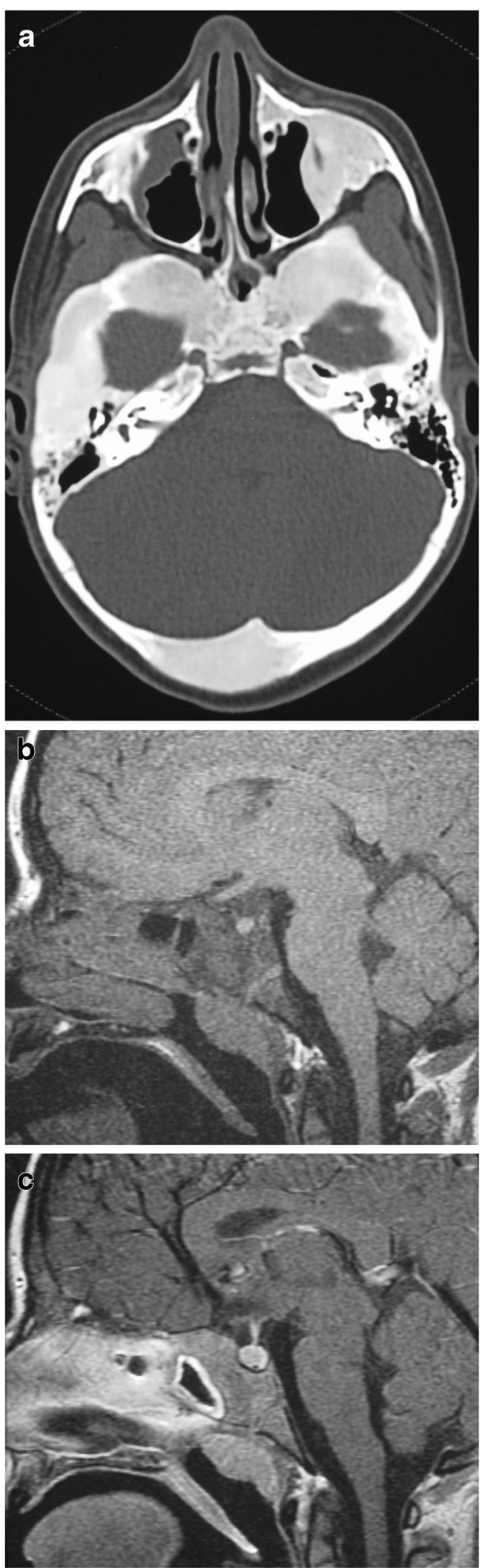
tive bone to mature lamellar bone with zones of immature trabeculae within dysplastic fibrous tissue. Craniofacial bones are involved in $10-20 \%$ of patients with the monostotic disease and in $50 \%$ of patients with the polyostotic form [64]. Patients range in age from $<1$ year to the eighth or ninth decades of life with $75 \%$ occurring before the age of 30 years. MRI features depend on the proportions of bony spicules, collagen, fibroblastic spindle cells, haemorrhagic and/or cystic changes, and if associated pathological fractures are present. Lesions are usually well-circumscribed and have low-intermediate signal on T1WI and proton-density weighted imaging (PDWI). On T2WI, lesions have variable mixtures of low, intermediate and/ or high signal often surrounding by a low signal rim of variable thickness. Internal septations and cystic changes are seen in a minority of lesions. Bone expansion with thickened and/or thinned cortex can be seen. Lesions show contrast enhancement varying in degree and pattern [65].

McCune-Albright syndrome Refers to an uncommon disorder in which polyostotic fibrous dysplasia is associated with pigmented cutaneous macules (café-au-lait spots) with irregular indented borders, precocious puberty, and/or other endocrine disorders such as acromegaly, hyperthyroidism, hyperparathyroidism, and/or Cushing's syndrome. McCuneAlbright syndrome is uncommon and occurs in 2-3\% of patients with polyostotic fibrous dysplasia [66].

\section{Langerhans' cell histiocytosis (Fig. 28) Disorder of the} reticuloendothelial system in which bone-marrow-derived dendritic Langerhans' cells infiltrate various organs as focal lesions or in diffuse patterns. Langerhans cells have eccentrically located ovoid or convoluted nuclei within pale to eosinophilic cytoplasm. Lesions often consist of Langerhans cells, macrophages, plasma cells and eosinophils. Prevalence of 2 per 100,000 children less than 15 years [67], with only a third of the lesions occurring in adults. Localised lesions (eosinophilic granuloma) can be single or multiple in the skull, usually at the skull base. There is a striking preference for LCH to involve regions without a blood brain barrier, with the hypothalamic-pituitary axis the most frequently involved intracranial region [68], with patients often presenting with diabetes insipidus. MRI will typically show a fusiform or lobulated lesion with intermediate signal on T1WI and T2WI involving the pituitary stalk. The pituitary stalk is usually $>3 \mathrm{~mm}$ in thickness [69], and is often associated with a loss of high signal on T1WI of the posterior pituitary. Lesions involving the pituitary usually show contrast enhancement [70].

Lymphocytic hypophysitis (Fig. 29) Rare autoimmune inflammatory process involving the pituitary gland confirmed by biopsy showing varying degrees of lymphocytic infiltration and plasma cells with fibrotic changes without multinucleated giant cells. They are more prevalent in women $(80 \%)$
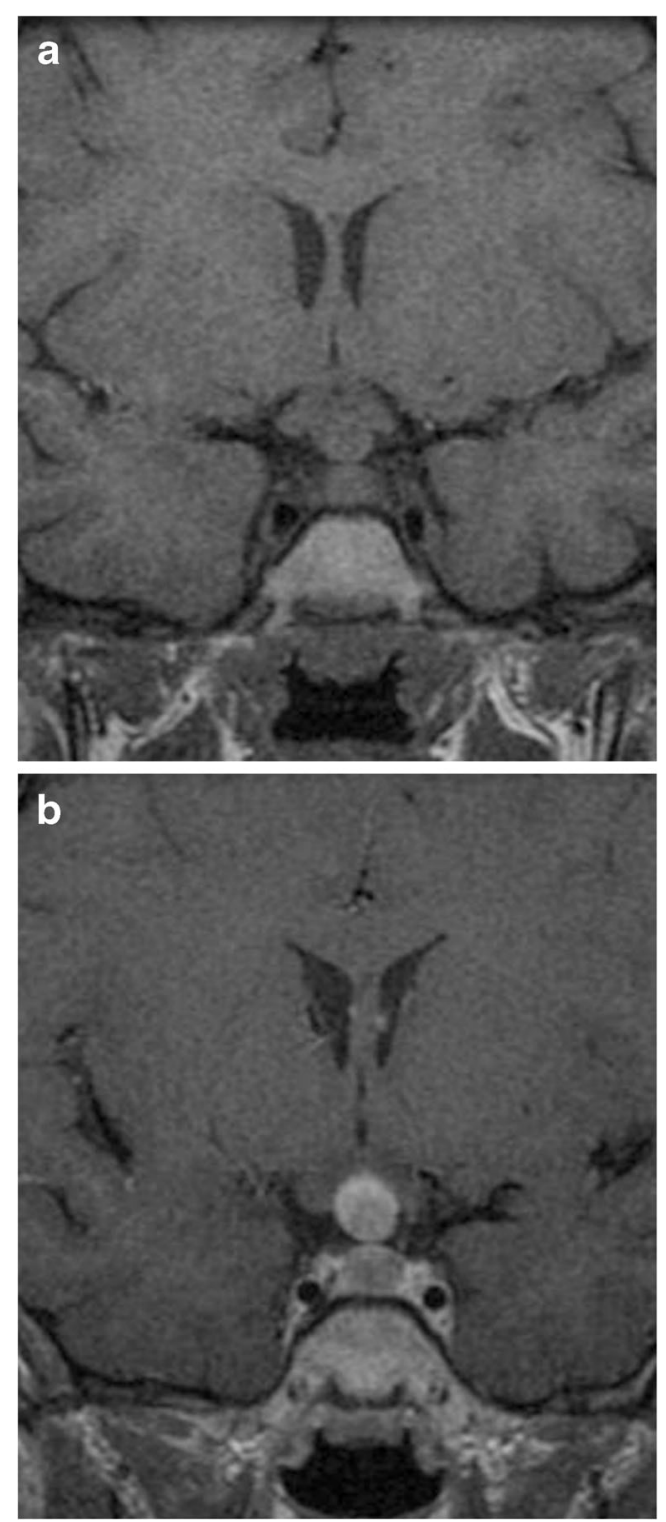

Fig. 28 Langerhans cell histiocytosis in a 6-year-old girl with headaches and diabetes insipidus. Coronal T1WI shows a lesion involving the upper pituitary gland and stalk which has intermediate signal (a). The lesion shows prominent enhancement on post-contrast coronal T1WI (b)

who are in late pregnancy or postpartum but can also occur in children. Clinical findings include headaches and pituitary hormonal dysfunction, with deficiency of ACTH in adults and growth hormone in children [71]. Lesions can be associated with Hashimoto thyroiditis, polymyositis, pernicious anaemia, atrophic gastritis, psoriasis, systemic lupus erythematosus, adrenalitis and/or ovarian failure. MRI shows a slightly lobulated lesion with intermediate signal on T1WI, heterogeneous low-intermediate and high signal on T2WI involving the pituitary lobe with thickened pituitary stalk, and prominent homogeneous or heterogeneous contrast enhancement involving the pituitary gland, pituitary stalk and dura. A 

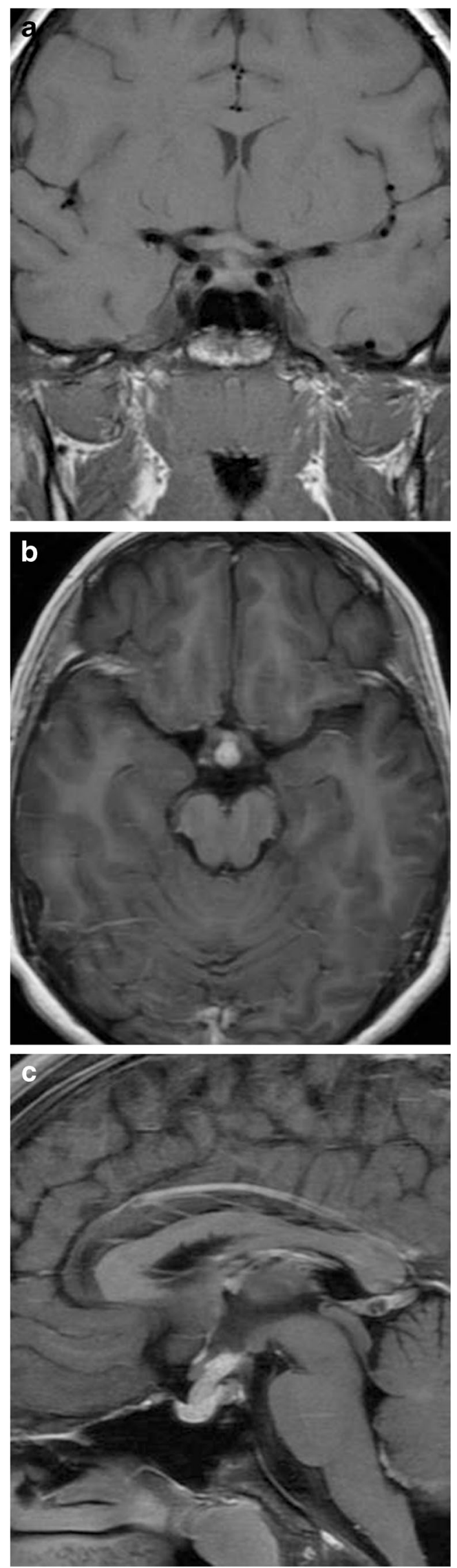

Fig. 29 Lymphocytic hypophysitis in a 16-year-old boy who presented with frequent urination, which started when he was 9. Coronal T1WI (a) shows thickening of the pituitary stalk which has intermdiate signal. Postcontrast axial (b) and sagittal (c) T1WI shows thickening of the pituitary stalk with homogeneous enhancement

characteristic finding includes a parasellar T2 dark sign, which helps in determining lymphocytic hypophysitis from a pituitary adenoma [72].

Rosai-Dorfman disease A rare benign histiocytosis, also referred to as sinus histiocytosis with massive lymphadenopathy. It usually occurs in children and young adults, with a male-female ratio of 3:2 [73]. Patients may present with painless adenopathy with one or more extranodal sites. When there is intracranial involvement, patients may present with headaches, seizures, visual disturbances, numbness and/or paraplegia. Involvement of the central nervous system (CNS) occurs in $4 \%$ and usually involves the intracranial or spinal dura, rarely occurring in the sella and suprasellar region. On MRI, suprasellar/sellar masses tend to be isointense on T1WI and hypointense/isointense on T2WI with homogeneous enhancement, and may be mistaken as a meningioma. A central hypointensiity on T2WI, thought to be related to free radicals release by inflammatory macrophages, may help distinguish from a meningioma [74, 75].

Lymphomatous leptomeningial metastases (Fig. 30) Primary CNS lymphoma is extremely rare in children, and usually occurs as intra-axial lesions and infrequently as leptomeningeal tumour. Most cases are non-Hodgkin, highgrade B-cell lymphomas. There is a strong link in patients with AIDS or primary immunodeficiency [76]. Leptomeningeal metastases can also be seen with acute lymphoblastic leukaemia, medulloblastomas, germ-cell tumours, ependymomas and malignant gliomas [77].

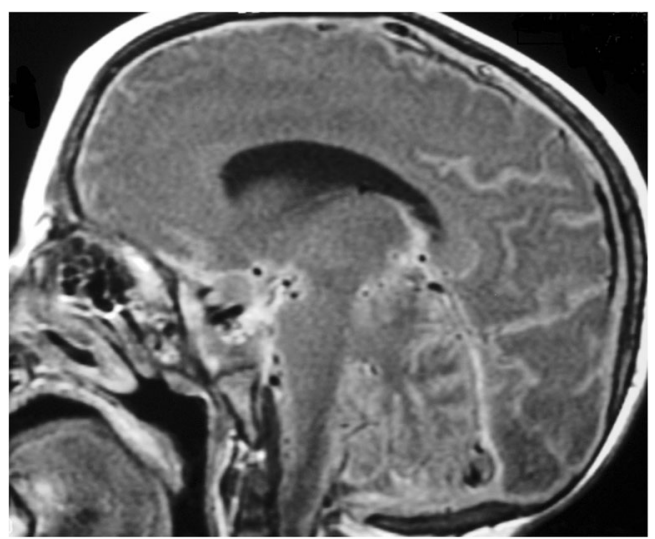

Fig. 30 Leptomeningeal spread of lymphoma. Sagittal post contrast T1WI demonstrates diffuse intracranial and spinal leptomeningeal enhancement in a 22-month-old infant boy with lymphoma including the sella and parasellar subarachnoid space 

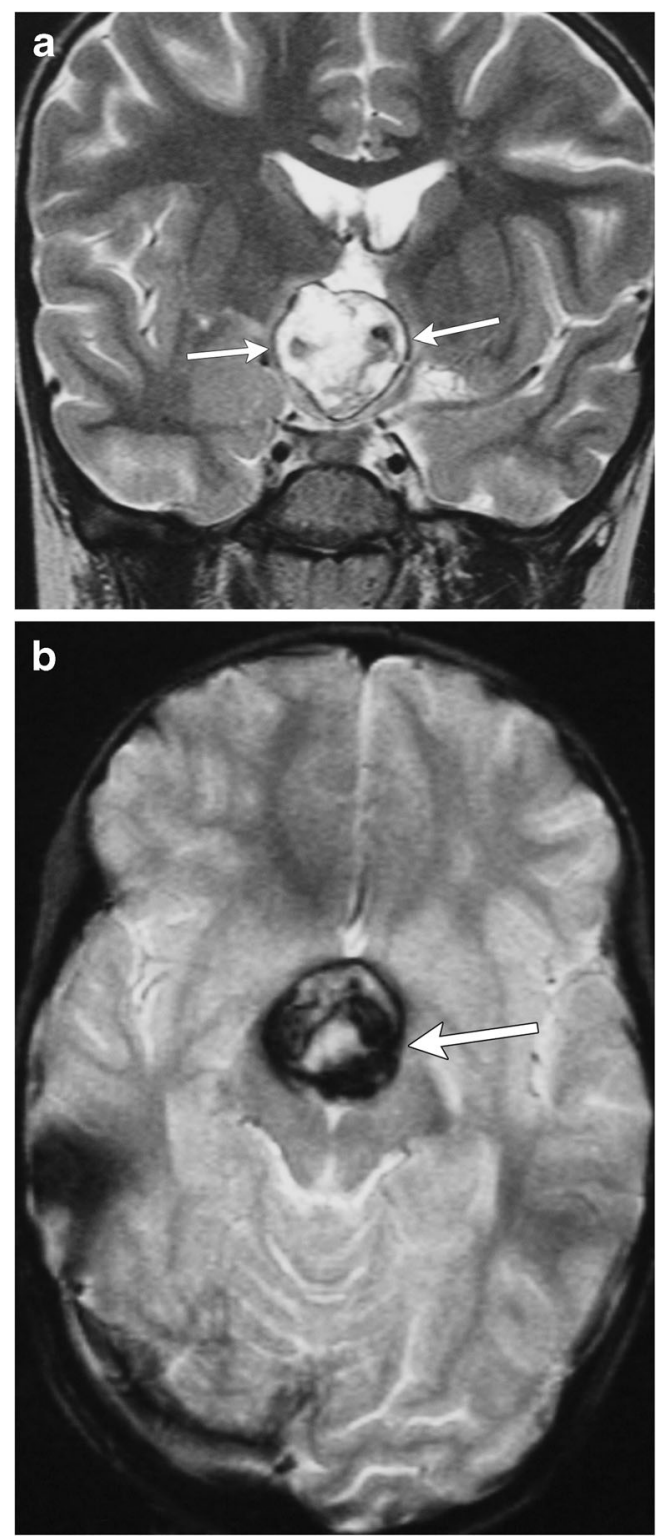

Fig. 31 Cavernous malformation: coronal T2WI (a) and axial gradient echo (GRE) (b) images in a 5-year-old girl show a large suprasellar lesion with mixed low, intermediate and high signal intensity with a thin rim of low signal on T2WI and foci of low T2* signal from susceptibility effects of blood products on GRE

\section{Vascular malformations (Fig. 31) Numerous vascular} malformations can be seen in the sellar/juxtasellar regions, including arterial aneurysms (saccular or giant aneurysms of the internal carotid artery [ICA]), cavernous carotid fistulas, arterial-venous malformations, haemangiomas or cavernous malformations. Cavernous malformations are the most common CNS vascular lesions in children, although the incidence is lower than in adults [78]. Compared to adults, these lesions are more aggressive in children with high rates of growth and haemorrhage, and a mean age of presentation of 9-10 years
[79]. MRI findings will show single or multiple multilobulated intra-axial lesions with a peripheral or irregular zone of low signal on T2WI and T2* secondary to haemosiderin, with a central zone of variable signal on T1WI and T2WI depending on ages of haemorrhagic components. Contrast enhancement is usually absent.

\section{Conclusions}

Imaging of the sellar and juxtasellar region in the paediatric population is ideally performed with MRI, and relies on a strong fundamental knowledge of the anatomy and signal characteristics of a normal gland and surrounding structures. The knowledge of key differentiating MRI characteristics in common and uncommon disease entities of the paediatric sellar and juxtasellar regions, in conjunction with the clinical findings, undoubtedly aids in alerting and guiding the clinician down the appropriate path of management. It is best to approach a suspected sellar or juxtasellar abnormality with an open mind and a broad differential, with MRI being the "gold standard" of imaging to accurately characterise these lesions.

Disclosures/Conflicts of Interest No funding source was used for this project. There are no relevant financial disclosures or conflicts of interest from any of the authors.

Open Access This article is distributed under the terms of the Creative Commons Attribution License which permits any use, distribution, and reproduction in any medium, provided the original author(s) and the source are credited.

\section{References}

1. Delman BN (2009) Imaging of pediatric pituitary abnormalities. Endocrinol Metab Clin N Am 38:673-698

2. Dietrich RB, Lis LE, Greensite FS, Pitt D (1995) Normal MR appearance of the pituitary gland in the first 2 years of life. AJNR Am J Neuroradiol 16:1413-1419

3. Fujisawa I, Asato R, Nishimura K et al (1987) Anterior and posterior lobes of the pituitary gland: assessment by $1.5 \mathrm{~T}$ MR imaging. $\mathrm{J}$ Comput Assist Tomogr 11:214-220

4. Nishimura K, Fujisawa I, Togashi K et al (1986) Posterior lobe of the pituitary: identification by lack of chemical shift artifact in MR imaging. J Comput Assist Tomogr 10:899-902

5. Fujisawa I, Asato R, Kawata M et al (1989) Hyperintense signal of the posterior pituitary on T1-weighted MR images: an experimental study. J Comput Assist Tomogr 13:371-377

6. Kiortsis D, Xydis V, Drougia AG et al (2004) The height of the pituitary in preterm infants during the first 2 years of life: An MRI study. Neuroradiology 46:224-226 
7. Takano K, Utsunomiya H, Ono H et al (1999) Normal development of the pituitary gland: assessment with three-dimensional MR volumetry. AJNR Am J Neuroradiol 20:312-315

8. Cervantes LF, Altman NR, Medina LS (2006) Case 102: pituitary aplasia. Radiology 241:936-938

9. Hamilton J, Blaser S, Daneman D (1998) MR imaging in idiopathic growth hormone deficiency. AJNR Am J Neuroradiol 19:1609-1615

10. Kelly WM, Kucharczyk W, Kucharczyk J et al (1988) Posterior pituitary ectopia: An MR feature of pituitary dwarfism. Am J Neuroradiol 9:453-460

11. Cohen LE, Radovick S (2002) Molecular basis of combined pituitary hormone deficiencies. Endocr Rev 23:431-442

12. Pellegrini-Bouiller I, Bélicar P, Barlier A et al (1996) A new mutation of the gene encoding the transcription factor Pit-1 is responsible for combined pituitary hormone deficiency. J Clin Endicrinol Metab 81: 2790-2796

13. Spampinato MV, Castillo M (2005) Congenital pathology of the pituitary gland and parasellar region. Top Magn Reson Imaging 16: 269-276

14. Hamilton BE, Salzman KL, Osborn AG (2007) Anatomic and pathologic spectrum of pituitary infundibulum lesions. AJR Am J Roentgenol 188:W223-W232

15. Di Iorgi N, Iorgi ND, Allegri AEM et al (2012) The use of neuroimaging for assessing disorders of pituitary development. Clin Endocrinol (Oxf) 76:161-176

16. Slavotinek A, Parisi M, Heike C et al (2005) Craniofacial defects of blastogenesis: duplication of pituitary with cleft palate and orophgaryngeal tumors. Am J Med Genet A 135:13-20

17. Kollias SS, Ball WS, Prenger EC (1995) Review of the embryologic development of the pituitary gland and report of a case of hypophyseal duplication detected by MRI. Neuroradiology 37:3-12

18. Manjila S, Miller EA, Vadera S et al (2012) Duplication of the pituitary gland associated with multiple blastogenesis defects: duplication of the pituitary gland (DPG)-plus syndrome. Case report and review of literature. Surg Neurol Int 3:23

19. Vittore CP, Murray RA, Martin LS (2005) Case 79: pituitary duplication. Radiology 234:411-414

20. Boyko OB, Curnes JT, Oakes WJ, Burger PC Hamartomas of the tuber cinereum: CT, MR, and pathologic findings. AJNR Am J Neuroradiol 12:309-314

21. Saleem SN, Said A-HM, Lee DH (2007) Lesions of the hypothalamus: MR imaging diagnostic features. Radiographics 27:1087-1108

22. Freeman JL, Coleman LT, Wellard RM et al (2004) MR imaging and spectroscopic study of epileptogenic hypothalamic hamartomas: analysis of 72 cases. AJNR Am J Neuroradiol $25: 450-462$

23. Chen CJ (2001) Suprasellar and infrasellar craniopharyngioma with a persistent craniopharyngeal canal: case report and review of the literature. Neuroradiology 43:760-762

24. Kaushik C, Ramakrishnaiah R, Angtuaco EJ (2010) Ectopic pituitary adenoma in persistent craniopharyngeal canal: case report and literature review. J Comput Assist Tomogr 34:612-614

25. Kucharczyk W, Peck WW, Kelly WM et al (1987) Rathke cleft cysts: CT, MR imaging, and pathologic features. Radiology 165:491-495

26. Nemoto Y, Inoue Y, Fukuda T et al (1988) MR appearance of Rathke's cleft cysts. Neuroradiology 30:155-159

27. Takanashi JI, Tada H, Barkovich AJ et al (2005) Pituitary cysts in childhood evaluated by MR imaging. Am J Neuroradiol 26:2144 2147

28. Byun WM, Kim OL, Kim DS (2000) MR imaging findings of Rathke's cleft cysts: significance of intracystic nodules. AJNR Am J Neuroradiol 21:485-488
29. Binning MJ, Liu JK, Gannon J et al (2008) Hemorrhagic and nonhemorrhagic Rathke cleft cysts mimicking pituitary apoplexy. J Neurosurg 108:3-8

30. Brassier G, Morandi X, Tayiar E et al (1999) Rathke's cleft cysts: surgical-MRI correlation in 16 symptomatic cases. J Neuroradiol 26 : 162-171

31. Kim JE, Kim JH, Kim OL et al (2004) Surgical treatment of symptomatic Rathke cleft cysts: clinical features and results with special attention to recurrence. J Neurosurg 100:33-40

32. Jabre A, Tabaddor R, Samaraweera R, Hahn YS (2000) Transsphenoidal meningoencephalocele in adults. Surg Neurol 54: $183-188$

33. Ruscalleda J (2005) Imaging of parasellar lesions. Eur Radiol 15: 549-559

34. Pisaneschi M, Kapoor G (2005) Imaging the sella and parasellar region. Neuroimaging Clin N Am 15:203-219

35. Gelabert-González M (1998) Intracranial epidermoid and dermoid cysts. Rev Neurol 27:777-782

36. Smith JK (2005) Parasellar tumors: suprasellar and cavernous sinuses. Top Magn Reson Imaging 16:307-315

37. Venkatesh SK, Phadke RV, Trivedi P, Bannerji D (2002) Asymptomatic spontaneous rupture of suprasellar dermoid cyst: a case report. Neurol India 50:480-483

38. Indulkar S, Hsich GE (2011) Spontaneous rupture of intracranial dermoid cyst in a child. Neurology 77:2070

39. Güzel A, Trippel M, Ostertage CB (2007) Suprasellar arachnoid cyst: a 20-year follow-up after stereotactic internal drainage: case report and review of the literature. Turk Neurosurg 17:211-218

40. Rengachary SS, Watanabe I (1981) Ultrastructure and pathogenesis of intracranial arachnoid cysts. J Neuropathol Exp Neurol 40:61-83

41. Choi JU, Kim DS (1998) Pathogenesis of arachnoid cyst: Congenital or traumatic? Pediatr Neurosurg 29:260-266

42. Di Pietro P, Debbia C, Paola Fondelli M (2004) Pediatric hypothalamic lipoma with hypothermia - case report. Brain Dev 26:61-62

43. Kurt G, Dogulu F, Kaymaz M et al (2002) Hypothalamic lipoma adjacent to mamillary bodies. Childs Nerv Syst 18:732-734

44. Sage MR, Blumbergs PC (2000) Primary empty sella turcica: a radiological-anatomical correlation. Australas Radiol 44:341348

45. Cacciari E, Zucchini S, Ambrosetto P et al (1994) Empty sella in children and adolescents with possible hypothalamic-pituitary disorders. J Clin Endocrinol Metab 78:767-771

46. Mindermann T, Wilson CB (1995) Pediatric pituitary adenomas. Neurosurgery 36:259-268, discussion 269

47. Partington MD, Davis DH, Laws ER, Scheithauer BW (1994) Pituitary adenomas in childhood and adolescence. Results of transsphenoidal surgery. J Neurosurg 80:209-216

48. Pandey P, Ojha BK, Mahapatra AK (2005) Pediatric pituitary adenoma: a series of 42 patients. J Clin Neurosci 12:124-127

49. Ginat DT, Meyers SP (2012) Intracranial lesions with high signal intensity on T1-weighted MR images: differential diagnosis. Radiographics 32:499-516

50. Rao AA, Naheedy JH, Chen JYY et al (2013) A clinical update and radiologic review of pediatric orbital and ocular tumors. J Oncol. doi: $10.1155 / 2013 / 975908$

51. Linscott L, Osborn AG, Blaser S et al (2008) Pilomyxoid astrocytoma: expanding the imaging spectrum. AJNR Am J Neuroradiol 29: $1861-1866$

52. Fernandez C, Figarella-Branger D, Girard N et al (2003) Pilocytic astrocytomas in children: prognostic factors - a retrospective study of 80 cases. Neurosurgery 53:544-555 
53. Derman A, Shields M, Davis A et al (2013) Diseases of the sella and parasellar region: an overview. Semin Roentgenol 48:35-51

54. Jennings MT, Gelman R, Hochberg F (1985) Intracranial germ-cell tumors: natural history and pathogenesis. J Neurosurg 63:155-167

55. Liu Z, Lv X, Wang W et al (2014) Imaging characteristics of primary intracranial teratoma. Acta Radiol 55:874-881

56. Van den Bos F, Terken M, Ypma L et al (2004) Tuberculous meningitis and miliary tuberculosis in young children. Trop Med Int Health 9:309-313

57. Jinkins JR, Gupta R, Chang KH, Rodriguez-Carbajal J (1995) MR imaging of central nervous system tuberculosis. Radiol Clin N Am 33:771-786

58. Janse Van Rensburg P, Andronikou S, Van Toorn R, Pienaar M (2008) Magnetic resonance imaging of miliary tuberculosis of the central nervous system in children with tuberculous meningitis. Pediatr Radiol 38:1306-1313

59. Bernaerts A, Vanhoenacker FM, Parizel PM et al (2003) Tuberculosis of the central nervous system: Overview of neuroradiological findings. Eur Radiol 13:1876-1890

60. Gadwal SR, Gannon FH, Fanburg-Smith JC et al (2001) Primary osteosarcoma of the head and neck in pediatric patients: a clinicopathologic study of 22 cases with a review of the literature. Cancer 91:598-605

61. Cotterill SJ, Ahrens S, Paulussen M et al (2000) Prognostic factors in Ewing's tumor of bone: analysis of 975 patients from the European Intergroup Cooperative Ewing's Sarcoma Study Group. J Clin Oncol 18:3108-3114

62. Broich G, Pagliari A, Ottaviani F (1997) Esthesioneuroblastoma: a general review of the cases published since the discovery of the tumour in 1924. Anticancer Res 17:2683-2706

63. Broski SM, Hunt CH, Johnson GB et al (2012) The added value of 18 F-FDG PET/CT for evaluation of patients with esthesioneuroblastoma. J Nucl Med 53:1200-1206

64. Moore AT, Buncic JR, Munro IR (1985) Fibrous dysplasia of the orbit in childhood. Clinical features and management. Ophthalmology 92:12-20

65. Shah ZK, Peh WCG, Koh WL, Shek TWH (2005) Magnetic resonance imaging appearances of fibrous dysplasia. Br J Radiol 78: $1104-1115$
66. Bousson V, Rey-Jouvin C, Laredo JD et al (2014) Fibrous dysplasia and McCune-Albright syndrome: imaging for positive and differential diagnoses, prognosis, and follow-up guidelines. Eur J Radiol 83:1828-1842

67. (1996) A multicentre retrospective survey of Langerhans' cell histiocytosis: 348 cases observed between 1983 and 1993. The French Langerhans' Cell Histiocytosis Study Group. Arch Dis Child 75:17-24

68. Prayer D, Grois N, Prosch H et al (2004) MR imaging presentation of intracranial disease associated with Langerhans cell histiocytosis. AJNR Am J Neuroradiol 25:880-891

69. Maghnie M, Cosi G, Genovese E et al (2000) Central diabetes insipidus in children and young adults. N Engl J Med 343:998-1007

70. Louis DN, Ohgaki H, Wiestler OD et al (2007) The 2007 WHO classification of tumours of the central nervous system. Acta Neuropathol 114:97-109

71. Kalra AA, Riel-Romero RMS, Gonzalez-Toledo E (2011) Lymphocytic hypophysitis in children: a novel presentation and literature review. J Child Neurol 26:87-94

72. Nakata Y, Sato N, Masumoto T et al (2010) Parasellar T2 dark sign on MR imaging in patients with lymphocytic hypophysitis. AJNR Am J Neuroradiol 31:1944-1950

73. Rosai J, Dorfman RF (1972) Sinus histiocytosis with massive lymphadenopathy: a pseudolymphomatous benign disorder. Analysis of 34 cases. Cancer 30:1174-1188

74. Wu M, Anderson AE, Kahn LB (2001) A report of intracranial RosaiDorfman disease with literature review. Ann Diagn Pathol 5:96-102

75. Lou X, Chen Z, Wang F, Ma L (2012) MR findings of RosaiDorfman disease in sellar and suprasellar region. Eur J Radiol 81: 1231-1237

76. Batchelor T, Loeffler JS (2006) Primary CNS lymphoma. J Clin Oncol 24:1281-1288

77. Chamberlain MC (1995) A review of leptomeningeal metastases in pediatrics. J Child Neurol 10:191-199

78. Acciarri N, Galassi E, Giulioni M et al (2009) Cavernous malformations of the central nervous system in the pediatric age group. Pediatr Neurosurg 45:81-104

79. Lena G, Ternier J, Paz-Paredes A, Scavarda D (2007) Central nervous system cavernomas in children. Neurochirurgie 53:223-237 